\title{
Effect of non-condensation gas on pressure oscillation of submerged steam jet condensation
}

Quanbin Zhao Yuelei Cong Yingchun Wang Weixiong Chen Daotong Chong* Junjie Yan State Key Laboratory of Multiphase Flow in Power Engineering, Xi' an Jiaotong University, Xi'an 710049, PR China

\begin{abstract}
The effect of air with low mass fraction on the oscillation intensity and oscillation frequency of a submerged steam jet condensation is investigated under stable condensation region. With air mixing in steam, an obvious dynamic pressure peak appears along the jet direction. The intensity peak increases monotonously with the rise of steam mass flux and water temperature. Peak position moves downstream with the rise of air mass fraction. Moreover, when compared with that of pure steam jet, the oscillation intensity clearly decreases as air is mixed. However, when water temperature is lower than approximately $45^{\circ} \mathrm{C}$, oscillation intensity increases slightly with the rise of air mass fraction, and when water temperature is higher than $55{ }^{\circ} \mathrm{C}$, the oscillation intensity decreases greatly with the rise of air mass fraction. Both the first and second dominant frequencies decrease with rise of air mass fraction. Finally, effect of air mass fractions on the oscillation power of the first and second dominant frequency bands shows similar trends. Under low water temperature, the mixed air has little effect on the oscillation power of both first and second frequency bands. However, when water temperature is high, the oscillation power of both first and second frequency bands appears an obvious peak when air mass fraction is about $1 \%$. With further rise of air mass fraction, the oscillation power decreases gradually.
\end{abstract}

Keywords: submerged steam jet; condensation oscillation; air mass fraction; oscillation dominant frequency; oscillation power

\section{Introduction}

Steam submerged jet condensation has been used widely in the industry because of its characteristics of high heat transfer and mass exchange capacity. Steam jet condensation system has the characteristic of passive, no motion part and no electrical control. Therefore, it is widely used in the fast heat discharge systems and residual heat reutilization industry applications, such as pressure relief pool in boiler water reactor, refueling water storage tank in advanced light water reactor, steam ejector and steam water direct contact heat exchanger.

However, steam submerged jet can cause pressure oscillation in the water. Pressure oscillation leads incessant load on the water tank or other apparatus in the tank. Specifically, when pressure oscillation frequency is close to the natural frequency of the water tank or relevant apparatus in pool, the resonance phenomenon happens. This phenomenon should be taken into account and avoided in the system design. Thus, the original experimental data of steam jet condensation oscillation is needed in the design database of nuclear reactor plant or other steam jet condensation systems.

Numerous scholars have investigated the jet condensation oscillation for many years. Chan (1978) measured the dynamic pressure impulse of submerged steam jet with sonic speed. They found that the oscillation frequency decreased with the rise of water temperature and nozzle diameter. Moreover, the interface oscillation caused by expansion and compression was more 
suitable for the explanation explaining of condensation oscillation. Simpson and Chan (1982) investigated the condensation oscillation under subsonic jet. They found that the pressure oscillation was closely related to the bubble separation process, and the oscillation frequency was affected by the heat transfer and steam jet mass flux. Therefore, they built a relation between dimensionless frequency, Strouhal number, with Jacobi number and Reynolds number, which was used widely by later researchers (Cho et al., 2004; Damasio et al., 1985; Qiu et al., 2014). Fukuda (1982) also investigated the jet oscillation frequency under sonic and subsonic speeds. He proved that the oscillation frequency was proportional to the pool water subcooled degree and inversely proportional to the nozzle diameter. Nariai and Aya(1986) considered that pressure oscillation was induced by the balance action between the steam supply and condensation at the steam-water interface. They proposed three models for steam cavity at condensation oscillation (CO) region to predict the condensation oscillation intensity and oscillation frequency. Hong et al. (2012) researched the condensation oscillation at stable condensation (SC) region. Based on the varying of steam jet lengths, they proposed a one-dimensional oscillation model to predict the steam condensation oscillation frequency, and the predicted frequency well agreed with the dominant frequency they measured. Qiu et al. $(2014 ; 2015)$ investigated the pressure oscillation with sonic and supersonic jets. They found that steam mass flux, subcooled water temperature and the design pressure ratio all had great significant affect effects on the condensation oscillation frequency. Besides the condensation oscillation dominant frequency, a second dominant frequency was also found. Chong et al. (2015) proved that the second dominant frequency has always existed in the SC region, and the oscillation power of the second dominant frequency band was larger than that of the first dominant frequency band. Zhao et al. (2015) investigated the distribution characteristic of condensation oscillation intensity at sonic jet condensation. They found that along jet direction, an oscillation intensity peak exists. The oscillation peak was well corresponding to the steam plume tail. Chen et al. (2016) discovered the low-frequency oscillation in the jet wake region and proved that the oscillation is caused by turbulent vortex. On the basis of oscillation power distribution, the affected region of low-frequency oscillation is obtained. Tang et al. $(2013 ; 2015)$ investigated the acoustic characteristic of steam bubble condensation under different water temperatures and steam injection rates. They found that acoustic sound frequency increased with the rise of water subcooling and steam injection rate. However, the amplitude of acoustic sound increased first and then decreased with the rise of water subcooling. Su et al.(2002) proposed a criterion to predict the stability thresholds for the two-phase flow with lumped parameter method. The characteristic of density wave oscillation was investigated under different parameters. Moreover, the oscillation frequency correlation of density wave oscillation was obtained theoretically.

To sum up, most studies focus on the pure steam jet condensation. However, in the process of release pressure in a nuclear reactor, some non-condensable gas may be mixed in the steam, and this will change the jet condensation characteristic. Norman and Revankar (2010a, 2010b) found that heat transfer capacity would decrease when non-condensable gas was mixed in steam. For the steam-air mixture jet, thermal stratification occurred in the water pool when water temperature was above $40{ }^{\circ} \mathrm{C}$ and air mass fraction was below $0.5 \%$. Thermal stratification disappeared when water temperature was below $40{ }^{\circ} \mathrm{C}$ and air mass fraction was higher than $1.0 \%$. Liang and Griffith (1994) found that with non-condensable gas present, heat transfer resistance at the steam-water interface increased and the condensation process was greatly retarded. Therefore, the 
chugging process transformed into an oscillation jet. Chan and Yuen (1990) carried out direct-contact condensation experiments and investigated the effects of air on direct-contact condensation heat transfer. They correlated the average Nusselt number with the average steam-air Reynolds number and air concentration. Choi et al. (2002) experimentally investigated the heat transfer coefficient of direct contact condensation with non-condensable gas. They found that the condensation heat transfer coefficient decreased with the rise of air fraction and then they proposed a modified correction multiplier to predict the condensation heat transfer coefficient of steam-air mixture. Qu et al. (2015) researched condensation characteristic of steam-air mixture bubble experimentally and numerically. They found that non-condensable air inside the bubble was near the interface and deteriorated the condensation heat and mass transfer.

Song et al. (2001) considered the effect of non-condensable gas on the heat transfer of steam jet condensation and realized that non-condensable gas would also affect the characteristic of condensation oscillation. Experimental results indicated that the oscillation dominant frequency decreased with air mixing. Air had a great influence on the oscillation intensity at $\mathrm{CO}$ region, but little effect on the oscillation intensity at SC region.

Based on previous research, non-condensable gas has a great influence on submerged steam jet condensation. However, few researches focus on the condensation oscillation characteristic, especially on the effect of non-condensable gas on oscillation characteristic at the SC region and the distribution characteristic of steam jet condensation's oscillation intensity. Moreover, there are two dominant frequencies at stable condensation region (Chong et al., 2015; Qiu et al., 2014), though the effects of non-condensable gas on these two dominant frequencies, including the frequency and amplitude, are still unclear. To solve the abovementioned problems, the present study is performed to investigate the effect of non-condensable gas on the condensation oscillation characteristic at the $\mathrm{SC}$ region.

\section{Experimental apparatus and uncertainty}

\subsection{Experimental apparatus}

The experimental system of submerged steam jet in quiescent water is shown in figure 1 . The steam jet system, nozzle structure and data acquiring system are similar to those of Zhao et al. (2015). Air is supplied by an air compressor and an air storage tank is used to keep the air supply steady and continuous. Air flows from the air storage tank and is then heated to the required temperature of saturated steam. Finally, the heated air is injected into a steam flow pipe to mix with steam. To ensure that steam and air are mixed homogeneously, the mixture pipe is long enough before the nozzle. The test parameters are shown in table 1 and measurement point distribution is displayed in figure 2 .

Figure 1 Schematic diagram of the experimental system

Table 1 Test conditions in the experiment

Figure 2 Measurement distribution 


\subsection{Repeatability and uncertainty}

Similar to pure steam jet condensation oscillation, root mean square pressure oscillation intension is introduced to describe the average oscillation intensity.

$$
P=\sqrt{\frac{\sum_{i=1}^{N}\left(P_{i}-\bar{P}\right)^{2}}{N}}
$$

where $P_{i}$ is the instantaneous pressure, $N$ is the sample number and $\bar{P}=\frac{1}{N} \sum_{i=1}^{N} P_{i}$.

The experimental repeatability is then checked and verified. Figure 3 shows the repeatability of experiment under following condition: water temperature $T=40{ }^{\circ} \mathrm{C}$, steam mass flux $G_{s}=700 \mathrm{~kg} \cdot \mathrm{m}^{-2} \cdot \mathrm{s}^{-1}$, air mass fraction $A=2 \%$. The maximum deviation of oscillation intensity is no more than $0.8 \%$ between repeatability tests. The good consistency of two experimental results indicates that the experimental results are reliable.

Figure 3 Repeatability of experiments

In the experiment, high-frequency dynamic pressure sensors are used to measure pressure oscillation. The accuracy of the pressure sensors is $0.2 \%$, which have been calibrated by the Institute of Metrology \& Measurement. Noise level in the measurement environment is no more than $0.05 \mathrm{kPa}$. The maximum error of the data acquisition system is $0.025 \%$. According to the uncertainty analysis method used by Tian et al. (2016), the maximum uncertainty of dynamic pressure at some measurement points, such as nozzle outlet, even reaches $15.4 \%$. However, for most measurement points, the maximum uncertainty of dynamic pressure is less than $10.3 \%$. For the oscillation frequency, error is derived from the resolution of fast Fourier transform and uncertainty from the averaged frequency for different measurement points. Finally, the maximum uncertainties of oscillation frequency for the first and second dominant frequencies are no more than $8.5 \%$ and $5.1 \%$ respectively. All the data uncertainties are shown in Table 2.

Table 2 Measurement uncertainty

\section{Results and discussion}

When steam is jetted into water, pressure impulses are generated. According to previous research (Chong et al., 2015; Hong et al., 2012; Qiu et al., 2015), pressure oscillation is mainly caused by the steam condensation at steam water interface, and the pressure oscillation amplitude is influenced by the heat transfer characteristic of steam jet condensation. Thus, non-condensable gas will affect the condensation oscillation because air can retard steam condensation (Choi et al., 2002; Liang and Griffith, 1994). Figure 4 shows the effect of air on the dynamic pressure wave of steam jet condensation. When air is mixed in steam, pressure oscillation amplitude decreases slightly and oscillation frequency lessens simultaneously.

Figure 4 Effect of air on the dynamic pressure of steam jet condensation 


\subsection{Condensation oscillation intensity}

Figure 4 illustrates that mixed air in steam jet condensation influences both the amplitude and frequency of pressure oscillation signal. To clarify the air effect, oscillation intensity and frequency are discussed respectively in this paper. First, to study the effect of air on oscillation intensity, average oscillation intensity, expressed as Equation(1), is introduced as a characterization of pressure oscillation intensity.

Figure 5 presents the average oscillation intensity at different radial distances. Similar to pure steam jet, oscillation intensity of steam-air mixture jet attenuates gradually with the rise of radial distance. Thus, to clearly understand the effect of air on the character of condensation oscillation, the results at position of $R / D=3$ is discussed and analyzed as a representative.

Figure 5 Pressure oscillation intensity of steam-air mixture jet versus radial distances

The average oscillation intensity of the steam-air mixture jet is investigated under different steam mass fluxes and water temperatures. Figure 6 shows the axial distributions of pressure oscillation intension under different steam mass fluxes and water temperatures. Along the steam jet direction, oscillation intensity of the steam-air mixture jet increases initially and then decreases, an oscillation peak appears. In addition, the maximum oscillation intensity increases with the rise of steam mass flux, as shown in figure 6(a).

However, with the rise of water temperature, the maximum oscillation intensity of the steam-air mixture jet increases monotonously, as shown in figure 6(b). The characteristic is quite different from the condensation oscillation characteristic of pure steam jet. For pure steam jet, with rise of water temperature, oscillation intensity increases first. When water temperature is about $40-45{ }^{\circ} \mathrm{C}$, it decreases suddenly. When water temperature is above $45{ }^{\circ} \mathrm{C}$, oscillation intensity increases again (Zhao et al., 2015).
(a) versus steam mass flux
(b) versus water temperature

Figure 6 Pressure oscillation intensity of steam-air mixture jet

In addition, the effect of air mass fraction on pressure oscillation intensity is investigated. Figure 7 shows the distribution of pressure oscillation intensity at different air mass fractions. The pressure oscillation intensity of steam-air mixture is lower than that of pure steam. The axial position of the oscillation peak also moves downstream gradually with rise of air mass fraction. As reported by Zhao et al. (2015), the oscillation intensity peak is located at the end of the steam cavity. When air mass fraction increases, heat transfer coefficient of the steam-water interface decreases considerably (Choi et al., 2002; Liang and Griffith, 1994). Hence, to condense the steam with the same mass flux, the steam plume is prolonged to increase the heat transfer area. Therefore, the axial position of the oscillation intensity peak moves simultaneously downstream along with the increasing of steam cavity length.

However, under different water temperatures, the effect of different air mass fractions on condensation oscillation intensity is quite different. Under low temperature, average oscillation intensity increases slightly with the rise of air mass fraction. By contrast it decreases when water temperature is relatively high. The threshold water temperature ranges from $45{ }^{\circ} \mathrm{C}$ to $55^{\circ} \mathrm{C}$. For example, when $G_{\mathrm{s}}=400 \mathrm{~kg} \cdot \mathrm{m}^{-2} \cdot \mathrm{s}^{-1}$ and $T \leq 45^{\circ} \mathrm{C}$, the maximum oscillation intensity increases with 
the rise of air mass fraction. However, when $T \geq 55{ }^{\circ} \mathrm{C}$, the maximum oscillation intensity decreases gradually with the rise of air mass fraction, as shown in figure 8.

The characteristic of average oscillation intensity under different air mass fractions can be mainly attributed to the effect of air mass fraction on the oscillation of the steam-water interface. According to report of Hong et al. (2012), condensation oscillation is caused by the fluctuation of steam-water interface. When water temperature is low, steam is condensed rapidly and steam cavity is relatively small. Mixed air will impede the heat transfer at the steam-water interface. With the rise of air mass fraction, heat transfer capacity decreases monotonously. Meanwhile, the steam-water interface expands and its fluctuation amplitude increases. Thus, the condensation oscillation intensity increases with the rise of air mass fraction.

When water temperature is high, water condensation capacity decreases and steam cavity length increases. The steam-water interface fluctuates violently. When some air is mixed in steam, heat transfer capacity decreases and the steam-water interface increases. Then the fluctuation of the steam-water interface may be enhanced. However, when air mass fraction is excessive, the steam-water interface will be quite unstable because of the velocity gradient and density gradient between steam and water (Celata et al., 1986,1989; Gulawani et al., 2007; Heinze et al., 2015). The amount of steam bulk will separate from the steam cavity and will be carried away by the airstream. Accordingly, condensation oscillation intensity decreases with the rise of air mass fraction.
(a) $\mathrm{T}=40{ }^{\circ} \mathrm{C}$
(b) $T=55^{\circ} \mathrm{C}$

Figure 7 Axial distribution of pressure oscillation intensity under different air mass fractions

Figure 8 Oscillation intensity peak under different air mass fractions

\subsection{Frequency spectrum}

On the basis of figure 4, air mass fraction affects both the steam jet oscillation amplitude and the oscillation frequency. Therefore, in this work, the oscillation frequency spectrum is studied using the fast Fourier transform method. The frequency spectrum has two obvious dominant frequencies in the frequency spectrum which is similar to the frequency spectrum of pure steam jet oscillation. The two dominant frequencies of steam-air mixture jet oscillation are then compared under different axial positions, as shown in figure 9. Clearly, both the two dominant frequencies of jet oscillation remain the same regardless of their position. This characteristic matches wave propagation theory and is similar to the results of pure steam condensation oscillation reported by Chong et al.(2015) and Qiu et al.(2014).

Figure 9 Frequency spectrums of steam-air mixture jet oscillation under different axial positions

Figure 10 shows the effect of air on the oscillation frequency of steam jet condensation. Both first and second dominant frequencies decrease with air present. As the two dominant frequencies appear in the frequency spectrum, they will be separately studied and compared with the oscillation frequencies of pure steam jet.

Figure 10 Frequency spectrums of steam jet and steam-air mixture jet 
Figures 11 and 12 show the first and the second dominant frequency under different air mass fractions, respectively. Both the two dominant frequencies decrease monotonously with the rise of air mass fraction. For pure steam jet, the oscillation first dominant frequency ranges from $218.2 \mathrm{~Hz}$ to $489.3 \mathrm{~Hz}$. However, when $A=5 \%$, the first dominant frequency is only approximately half of that of pure steam jet condensation and the minimum frequency value decreases to 108.2 $\mathrm{Hz}$, which would be much closer to the resonance frequency of relevant equipments. In addition, under condition $A=5 \%$, the second dominant frequency is only in the range of 196.1-496.6 Hz. However, it is in the range of $488.2-1364.1 \mathrm{~Hz}$ with pure steam jet. The results indicate that the steam jet with air mixing is more likely to cause resonance in the industry.

The first dominant frequency is thought to be generated by steam-water interface oscillation caused by the simultaneous function of steam supply and vapor condensation (Hong et al., 2012; Qiu et al., 2015; Song and Kim, 2011). When air is mixed with steam, heat transfer resistance at the interface increases and heat transfer capacity decreases greatly. Afterward, the steam plume is prolonged. With a large interface, the oscillation period is extended and the oscillation frequency decreases. With the rise of air mass fraction, heat transfer coefficient decreases monotonously, the steam-water interface expands, and oscillation frequency decreases monotonously.

The second dominant frequency is proved to be caused by the separated steam bubble (Chong et al., 2015; Qiu et al., 2014) whose diameter depends on the steam plume. With the rise of air mass fraction, the steam plume is prolonged, steam-water interface is expanded, the rigidity of the steam plume weaken, and then the volume of steam bubble separated from the steam plume increases and its diameter increases ( $\mathrm{Xu}, 2004)$. According to the Rayleigh oscillation equation, bubble oscillation frequency is inversely proportional to the bubble diameter. As a result, the second dominant frequency also decreases with the rise of air mass fraction.

$\begin{array}{ll}\text { (a) under different water temperatures } & \text { (b) under different steam mass fluxes }\end{array}$

Figure 11 First dominant frequency versus air mass fraction

$\begin{array}{ll}\text { (a) under different water temperatures } & \text { (b) under different steam mass fluxes }\end{array}$

Figure 12 Second dominant frequency versus air mass fraction

\subsection{Oscillation power}

To investigate the effect mechanism of air on condensation oscillation, the oscillation power for each frequency band is investigated. The oscillation power of the first and second dominant frequency bands can be obtained from the frequency spectrum via Parseval's relation (Smith, 2003),

$$
E=\int_{t_{1}}^{t_{2}}|f(t)|^{2} \mathrm{~d} t=\frac{1}{2 \pi} \int_{\omega_{1}}^{\omega_{2}}|F(j \omega)|^{2} \mathrm{~d} \omega
$$

where $f(t)$ is the pressure oscillation signal in the time spectrum, and $t_{l}$ and $t_{2}$ are the time. $F(\omega)$ is the pressure signal in the frequency spectrum, which is transformed using fast Fourier transform. $\omega_{1}$ and $\omega_{2}$ stand for the frequencies. The effect of air on the oscillation power can then be investigated for each frequency band. The frequency band where the first dominant frequency locates is defined as the first frequency band. The boundary of the first frequency band, that is the $\omega_{1}$ and $\omega_{2}$, is defined as the frequency where all partial derivatives of the oscillation amplitude are 
zero. The same definition applies for the second frequency band.

First, the effect of air on the oscillation power of the first frequency band is investigated, as shown in figure 13. In figure 13(a), under low water temperature, the oscillation power of the first frequency band increases gradually with the rise of air mass fraction. However, under high water temperature, as shown in figure 13(b), when air mass fraction increases from $A=0 \%$ to $A=1 \%$, the oscillation power increases sharply, and, with the further rise of air mass fraction, the oscillation power decreases. The critical water temperature, at which oscillation power decreases with the further rise of air mass fraction, ranges from $45{ }^{\circ} \mathrm{C}$ to $55{ }^{\circ} \mathrm{C}$. For example, when $G_{s}=500$ $\mathrm{kg} \cdot \mathrm{m}^{-2} \cdot \mathrm{s}^{-1}$, the critical temperature is about $50^{\circ} \mathrm{C}$ as shown in figure $14(\mathrm{a})$. The maximum oscillation power also changes little when water temperature is less than $50^{\circ} \mathrm{C}$, but it increases sharply after $\mathrm{T} \geq 55^{\circ} \mathrm{C}$, as shown in figure $14(\mathrm{~b})$.
(a) $\mathrm{T}=30^{\circ} \mathrm{C}$
(b) $T=60^{\circ} \mathrm{C}$

Figure 13 Effect of air mass fraction on oscillation power of the first frequency band
(a) versus air mass fraction
(b) versus water temperature

Figure 14 Maximum oscillation power of the first frequency band versus air mass fraction and water temperature

The effect of air on the oscillation power of the second frequency band is similar to that on the first frequency band, as shown in figure 15 and figure 16 . The only difference is that under low water temperature, the oscillation power of the second frequency band decreases when mixed air mass fraction increases from $A=0 \%$ to $A=1 \%$. Then, as air is continuously added steam, the oscillation power increases gradually.

The results indicate that the mixed air has greater impact on the oscillation power of the first and second dominant frequencies under high water temperature than the effect under low water temperature. When water temperature is low oscillation power of both the first and second frequency bands increases slightly with the rise of air mass fraction. However, under high water temperature, the maximum oscillation power occurs under the cases of $A=1 \%$. When air mass fraction exceeds one percent, $A \geqslant 1 \%$, both oscillation power of the first and second dominant frequency bands decrease gradually with the rise of air mass fraction. This outcome is the reason why average oscillation intensity decreases under high water temperature.

Similar to the explanation for the effect of air on oscillation intensity, the oscillation power results are also attributed to the effect of air on the stability of steam-water interface and heat transfer at steam-water interface. Under high water temperature, water condensation capacity weakens. The steam-water interface is big and it fluctuates violently. When some air is mixed in steam, heat transfer capacity further decreases and the steam-water interface becomes bigger. The fluctuation of the steam-water interface can then be enhanced. However, when air mass fraction is excessive, the amount of steam bulk will separate from steam cavity owing to the instability of the steam-water interface and the separated steam will be carried out from water by the airstream. Therefore, an air mass fraction under which oscillation power reaches the maximum value must exist. According to our experiment, the air mass fraction is proved to be $A=1 \%$. The results are similar to the oscillation characteristic at the CO region reported by Song et al.(2001). 

(a) $\mathrm{T}=30^{\circ} \mathrm{C}$
(b) $\mathrm{T}=60{ }^{\circ} \mathrm{C}$

Figure15 Effect of air mass fraction on oscillation power of the second frequency band
(a) versus air mass fraction
(b) versus water temperature

Figure 16 Maximum oscillation power of the second frequency band versus air mass fraction and water temperature

The oscillation power comparisons of the first and the second frequency bands revealed that, under the test condition, when air mass fraction increases from $A=0 \%$ to $A=5 \%$, the maximum oscillation power of the second frequency band is always higher than that of the first frequency band, as shown in figure 17. This finding is similar to the results reported by Zhao et al.(2015). However, after $\mathrm{A}>1 \%$, the oscillation power gap between the two frequency bands decreases with the rise of air mass fraction.

$$
\text { (a) } A=0 \%
$$
(b) $A=1 \%$
(c) $A=5 \%$

Figure 17 Comparison of oscillation power between the first and second frequency band

To further investigate the effect of air mass fraction on the first and second frequency bands, the absolute variation of maximum oscillation power for the two frequency band is calculated. The absolute variation of oscillation power is defined as follows:

$$
\Delta E_{i}=E_{A=0 \%}-E_{A=i \%}
$$

where $i=1,2,3,4,5$.

Figure 18 shows the variation of maximum oscillation power under different air mass fraction. Variation of oscillation power under high water temperature is bigger than that under low temperature. On the other side, under different air mass fractions, the variation of oscillation power of the second frequency band is also bigger than that of the first frequency band. The results also point out that the effect of air mass fraction on the oscillation power of the second frequency band is greater than that on the first frequency band.

Figure 18 Variation of maximum oscillation power at different air mass fraction

\section{Conclusion}

The effect of air on the condensation oscillation characteristic of submerged steam jet at the SC region is investigated experimentally. Both the condensation oscillation intensity and oscillation frequency are found to change with the air mass fraction. The effect of air mass fraction on the oscillation power of the first and second frequency bands is discussed. The air mass fraction that has the strongest impact on oscillation power is found to be $A=1 \%$ under high water temperature. The main results are summarized as follows:

(1) With air mixing in steam, an obvious dynamic pressure peak appears along the jet direction. The intensity peak increases monotonously with the rise of steam mass fluxes and water 
temperatures. As air mass fraction increases, the peak position gradually moves downstream.

(2) The oscillation intensity of the steam-air mixture jet is lower than that of the pure steam jet. However, when water temperature is lower than $45^{\circ} \mathrm{C}$, the mixed air has little effect on the oscillation intensity; when water temperature is higher than $55{ }^{\circ} \mathrm{C}$, the oscillation intensity decreases greatly with the rise of air mass fraction.

(3) Both the first and second dominant frequencies decrease with the rise of air mass fraction because of the reduction of heat transfer coefficient at the steam-water interface. As air mass fraction increases to $5 \%$, the lowest value of the first and second dominant frequencies decreases from $489.3 \mathrm{~Hz}$ to $108.1 \mathrm{~Hz}$ and 488.2 to $196.1 \mathrm{~Hz}$, respectively.

(4) The effects of different air mass fractions on the oscillation power of the first and second frequency bands are similar: under low water temperature, the oscillation power of both the first and second frequency bands increases slightly with the mixed air mass fraction. When water temperature is high and air mass fraction is low, approximately $A=1.0 \%$, the oscillation power of both first and second frequency bands is the strongest. With a further rise of air mass fraction, the oscillation power of the first and second frequency bands decreases gradually.

\section{Acknowledgements:}

This work was supported by the National Science Foundation of China (No. 51476128, and No. 51506167), the National Key Basic Research Development Plan (No.2015CB251504).

\section{Figure Captions}

Figure 1 Schematic diagram of the experimental system

Figure 2 Measurement distribution

Figure 3 Repeatability of experiments

Figure 4 Effect of air on the dynamic pressure of steam jet condensation

Figure 5 Pressure oscillation intensity of steam-air mixture jet versus radial distances

Figure 6 Pressure oscillation intensity of steam-air mixture jet

Figure 7 Axial distribution of pressure oscillation intensity under different air mass fractions

Figure 8 Oscillation intensity peak under different air mass fractions

Figure 9 Frequency spectrums of steam-air mixture jet oscillation under different axial positions

Figure 10 Frequency spectrums of steam jet and steam-air mixture jet

Figure 11 First dominant frequency versus air mass fraction

Figure 12 Second dominant frequency versus air mass fraction

Figure 13 Effect of air mass fraction on oscillation power of the first frequency band

Figure 14 Maximum oscillation power of first frequency band versus air mass fraction and water temperature

Figure15 Effect of air mass fraction on oscillation power of the second frequency band Figure16 Maximum oscillation power of the second frequency band versus air mass fraction and water temperature

Figure 17 Comparison of oscillation power between the first and second frequency band Figure 18 Variation of maximum oscillation power at different air mass fraction

\section{Table Captions}


Table 1 Test conditions in experiment

Table 2 Measurement uncertainty 


\section{References:}

Celata, G. P., Cumo, M., Farello, G. E. ,Focardi, G., 1986. Direct contact condensation of steam on slowly moving water. Nuclear Engineering And Design. 96, 21-31.

Celata, G. P., Cumo, M., Farello, G. E. ,Focardi, G., 1989. A comprehensive analysis of direct contact condensation of saturated steam on subcooled liquid jets. International Journal Of Heat And Mass Transfer. 32, 639-654.

Chan, C. K., 1978. Dynamical pressure pulse in steam jet condensation. In Proc. 6th Int. Heat Transfer Conf., Toronto, 395-399.

Chan, T. S. ,Yuen, M. C., 1990. The effect of air on condensation of stratified horizontal concurrent steam/water flow. Journal of heat transfer. 112, 1092-1095.

Chen, W., Zhao, Q., Wang, Y., Sen, P. K., Chong, D. ,Yan, J., 2016. Characteristic of pressure oscillation caused by turbulent vortexes and affected region of pressure oscillation. Experimental Thermal And Fluid Science. 76, 24-33.

Cho, S., Chun, S., Baek, W. ,Kim, Y., 2004. Effect of multiple holes on the performance of sparger during direct contact condensation of steam. Experimental Thermal And Fluid Science. 28, 629-638.

Choi, K. Y., Chung, H. J. ,No, H. C., 2002. Direct-contact condensation heat transfer model in RELAP5/MOD3. 2 with/without noncondensable gases for horizontally stratified flow. Nuclear Engineering And Design. 211, 139-151.

Chong, D., Zhao, Q., Yuan, F., Cong, Y., Chen, W. ,Yan, J., 2015. Experimental and theoretical study on the second dominant frequency in submerged steam jet condensation. Experimental Thermal And Fluid Science. 68, 744-758.

Damasio, C., Del Tin, G., Fiegna, G. ,Malandrone, M., 1985. Experimental study on the unstable direct contact condensation regimes. In Proc. of 3rd Int. Topical Meeting on Reactor Thermal Hydraulics, Newport, Rhode Island, 6.

Fukuda, S., 1982. pressure variation due to vapor condensation in liquid. Journal Of The Atomic Energy Society Of Japan. 24, 466-474.

Gulawani, S. S., Deshpande, S. S., Joshi, J. B., Shah, M. S., Prasad, C. ,Shukla, D. S., 2007. Submerged gas jet into a liquid bath: A review. Industrial \& Engineering Chemistry Research. 46, 3188-3218.

Heinze, D., Schulenberg, T. „Behnke, L., 2015. A Physically Based, One-Dimensional Two-Fluid Model for Direct Contact Condensation of Steam Jets Submerged in Subcooled Water. Journal of Nuclear Engineering and Radiation Science. 1, 21002.

Hong, S. J., Park, G. C., Cho, S. ,Song, C., 2012. Condensation dynamics of submerged steam jet in subcooled water. International Journal Of Multiphase Flow. 39, 66-77.

Liang, K., 1994. Experimental and analytical study of direct contact condensation of steam in water. Nuclear Engineering And Design. 147, 425-435.

Nariai, H. ,Aya, I., 1986. Fluid and pressure oscillations occuring at direct contact condensation of steam flow with cold water. Nuclear Engineering And Design. 95, 35-45.

Norman, T. L. ,Revankar, S. T., 2010a. Jet-plume condensation of steam - air mixtures in subcooled water, Part 1: Experiments. Nuclear Engineering And Design. 240, 524-532.

Norman, T. L. ,Revankar, S. T., 2010b. Jet-plume condensation of steam - air mixtures in subcooled water. Part 2: Code model. Nuclear Engineering And Design. 240, 533-537.

Qiu, B., Yan, J., Liu, J., Chong, D., Zhao, Q. ,Wu, X., 2014. Experimental investigation on the second 
dominant frequency of pressure oscillation for sonic steam jet in subcooled water. Experimental Thermal And Fluid Science. 58, 131-138.

Qiu, B., Yan, J., Liu, J. ,Chong, D., 2015. Experimental investigation on pressure oscillation frequency for submerged sonic/supersonic steam jet, 388-394.

Qu, X., Tian, M., Zhang, G. ,Leng, X., 2015. Experimental and numerical investigations on the air steam mixture bubble condensation characteristics in stagnant cool water. Nuclear Engineering And Design. 285, 188-196.

Simpson, M. E. ,Chan, C. K., 1982. Hydrodynamics of a subsonic vapor jet in subcooled liquid. Journal of Heat Transfer. 104, 271-278.

Smith, S. W.,2003. Chapter 10 - Fourier Transform Properties. In Digital Signal Processing (First), S. W. Smith, ed.eds. (Boston, Newnes), pp. 185-208.

Song, C., Cho, S., Kwon, T., Kim, K. Y. ,Chung, M. K., 2001. The Effect of Non-condensable Gas on Dynamic Pressure Induced by Steam-Water Direct Contact Condensation. ASME-PUBLICATIONS-PVP. 421, 193-200.

Song, C. ,Kim, Y., 2011. Direct Contact Condensation of Steam Jet in a Pool. Advances in Heat Transfer. 43, 227.

Su Guanghui, Jia Dounan, Kenji Fukuda, Guo Yujun, 2002. Theoretical and experimental study on density wave oscillation of two-phase natural circulation of low equilibrium quality. Nuclear Engineering and Design. 215, 187-198.

Tang, J., Zhu, G. ,Sun, L., 2013. Microbubble emission boiling in scbcooled pool boiling and the role of Marangoni convection in its formation. Experimental Thermal And Fluid Science. 50, 97-106.

Tang, J., Yan, C., Sun, L., Li, Y. ,Wang, K., 2015. Effect of liquid subcooling on acoustic characteristics during the condensation process of vapor bubbles in a subcooled pool. Nuclear Engineering And Design. 293, 492-502.

W.X. Tian, K. Zhang, Y.D. Hou, Y.P. Zhang, S.Z. Qiu, G.H. Su, 2016. Hydrodynamics of two-phase flow in a rod bundle under cross-flow condition. Annals of Nuclear Energy. 91, 206-214.

Xu, Y., 2004. Direct contact condensation with and without non condensing gas in a water pool. Purdue University, West lafayette.

Zhao, Q., Chen, W., Yuan, F., Wang, W., Chong, D. ,Yan, J., 2015. Pressure oscillation and steam cavity during the condensation of a submerged steam jet. Annals Of Nuclear Energy. 85, 512-522. 
Table 1 Test conditions in experiment

\begin{tabular}{cc}
\hline Parameters & value \\
\hline Nozzle diameter, $D$ & $8 \mathrm{~mm}$ \\
Steam mass flux, $G_{s}$ & $400-800 \mathrm{~kg} \cdot \mathrm{m}^{-2} \cdot \mathrm{s}^{-1}$ \\
Air mass fraction, $A$ & $0,1,2,3,4,5 \%$ \\
Water temperature, $T$ & $25-65^{\circ} \mathrm{C}$ \\
Dimensionless radial distance, $R / D$ & $3,4,5$ \\
Dimensionless axial distance, $X / D$ & $0-15$ \\
\hline
\end{tabular}


Table 2 Measurement uncertainty

\begin{tabular}{lcc}
\hline Instrument function & Range & Uncertainty \\
\hline Steam mass flux & $400-800 \mathrm{~kg} \cdot \mathrm{m}^{-2} \cdot \mathrm{s}^{-1}$ & $0.5 \%$ \\
Air mass flux & $0-40 \mathrm{~kg} \cdot \mathrm{m}^{-2} \cdot \mathrm{s}^{-1}$ & $0.5 \%$ \\
Water temperature & $25-65{ }^{\circ} \mathrm{C}$ & $0.5{ }^{\circ} \mathrm{C}$ \\
Dynamic pressure & $0-100 \mathrm{kPa}$ & $10.3 \%$ \\
The first dominant frequency & $0-600 \mathrm{~Hz}$ & $8.5 \%$ \\
The second dominant frequency & $0-1500 \mathrm{~Hz}$ & $5.1 \%$ \\
\hline
\end{tabular}




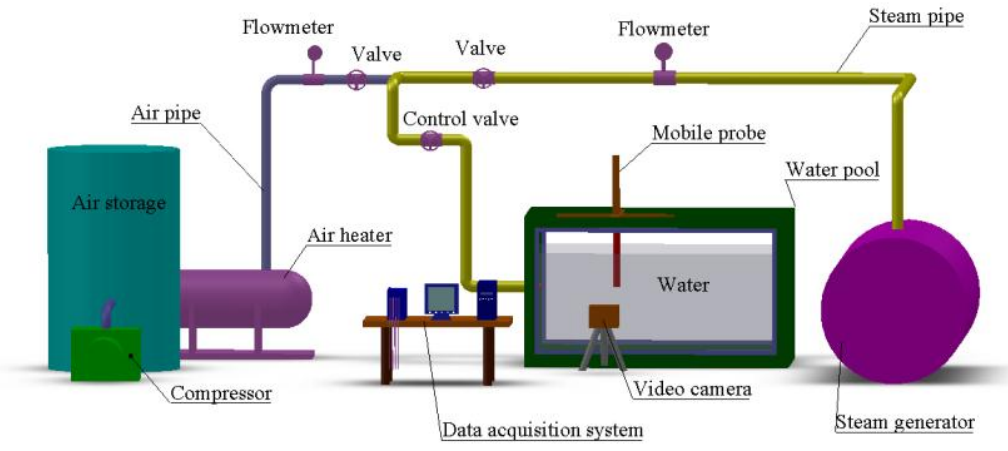




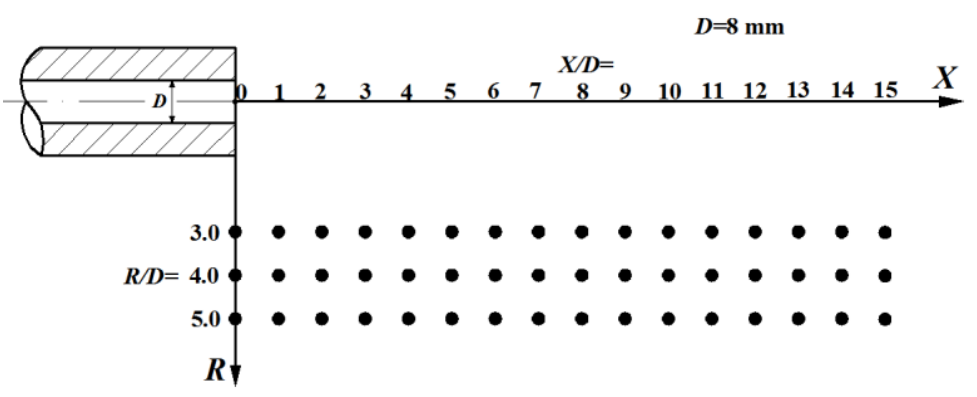




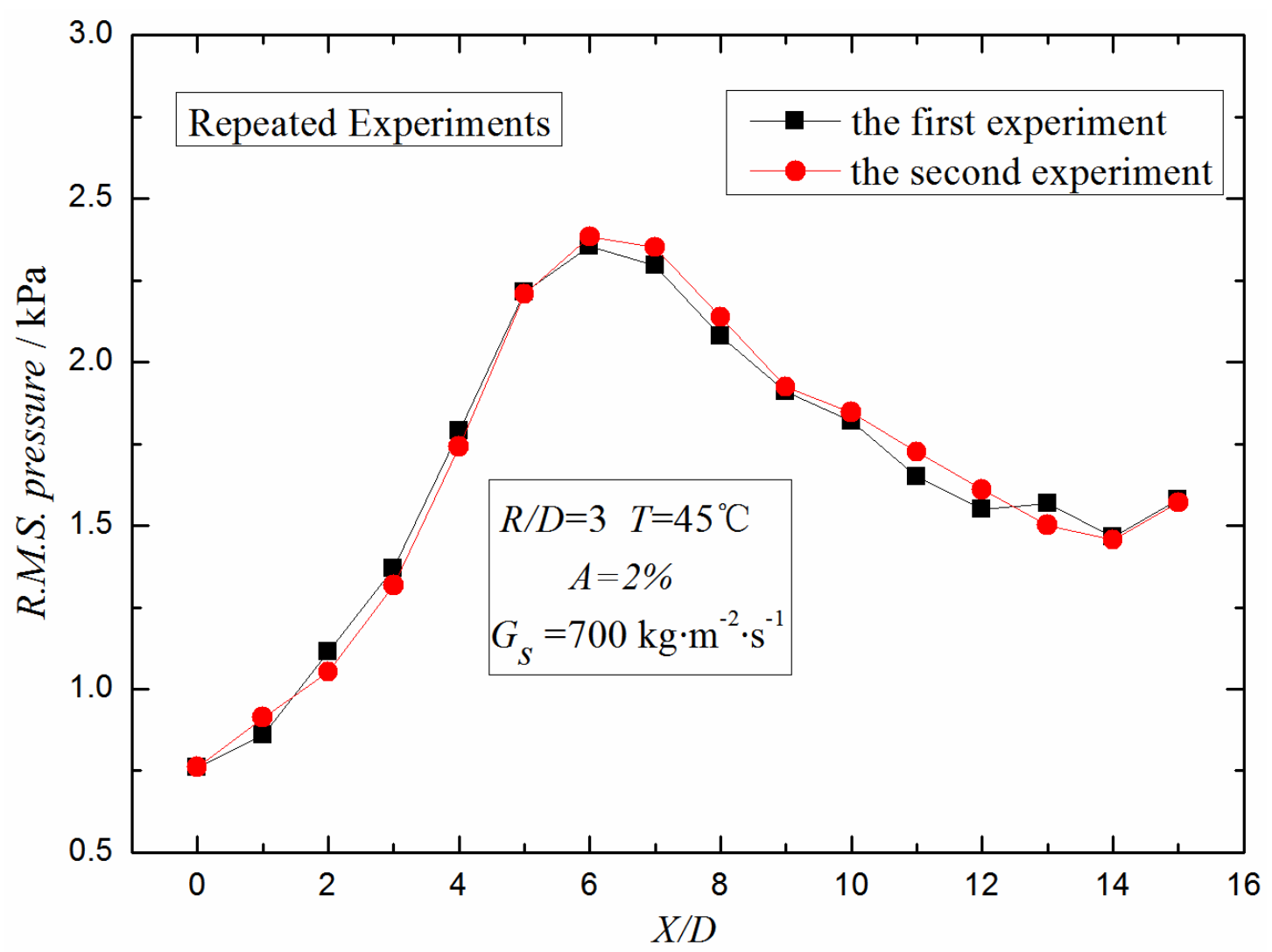




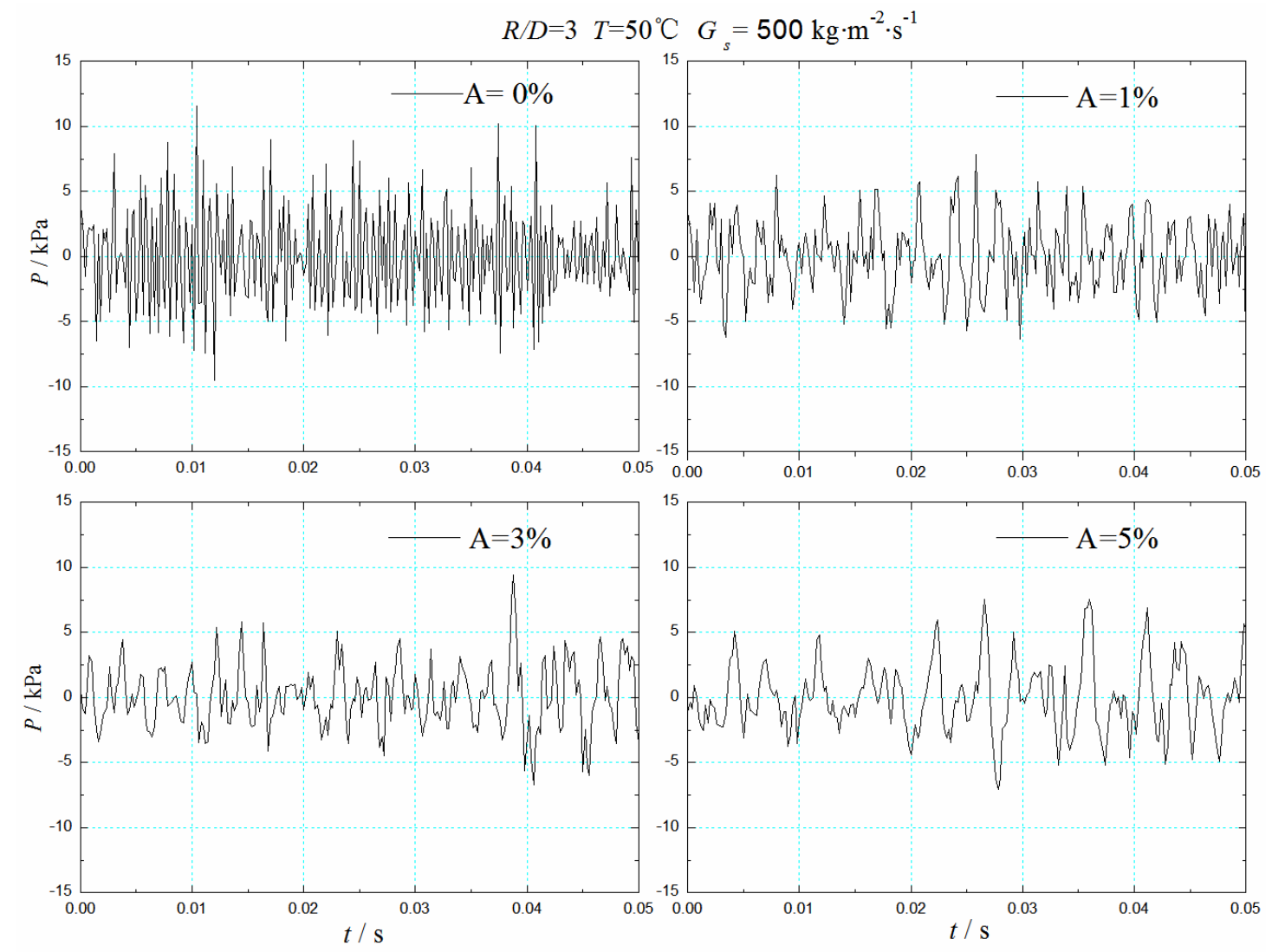




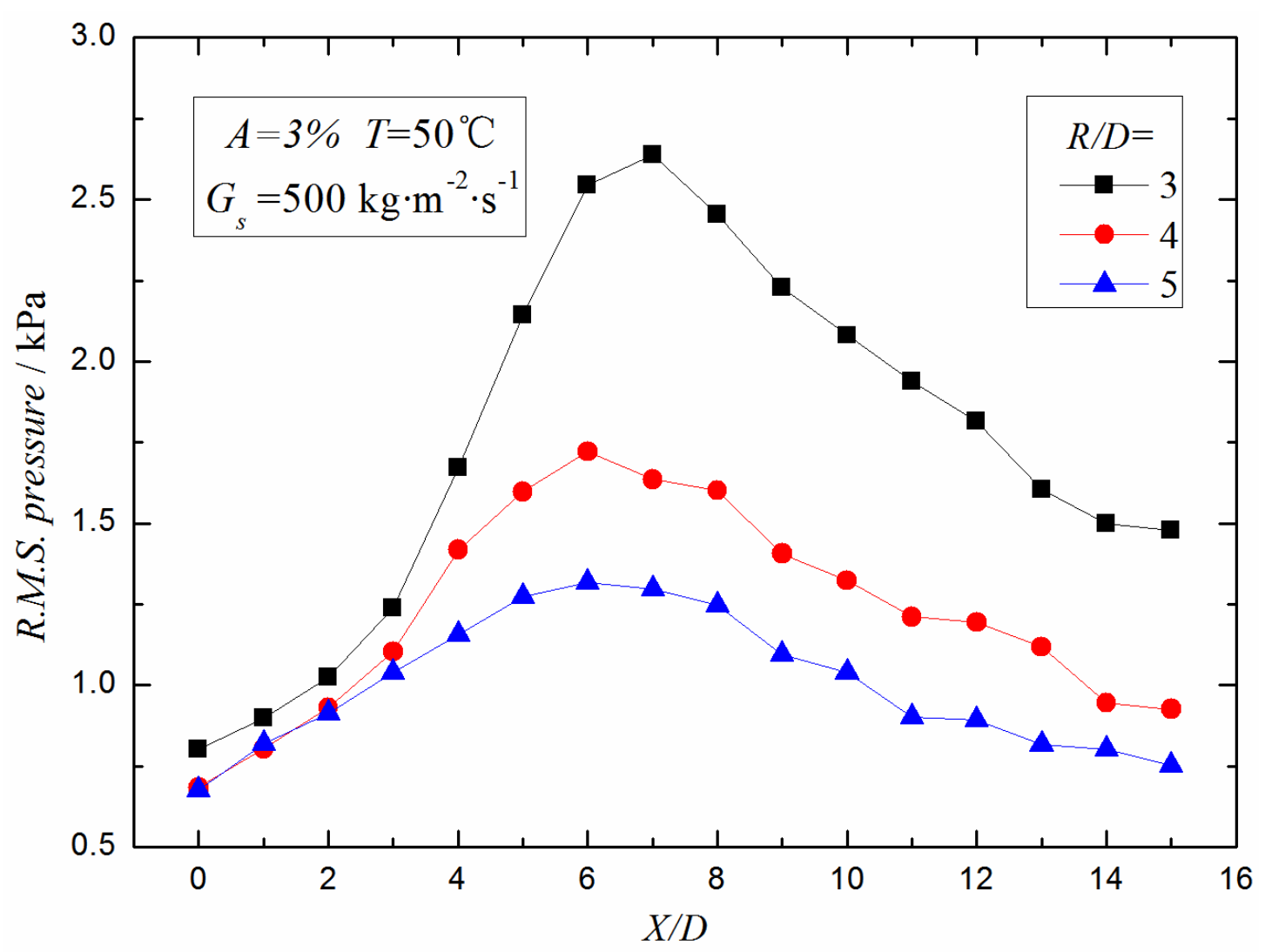




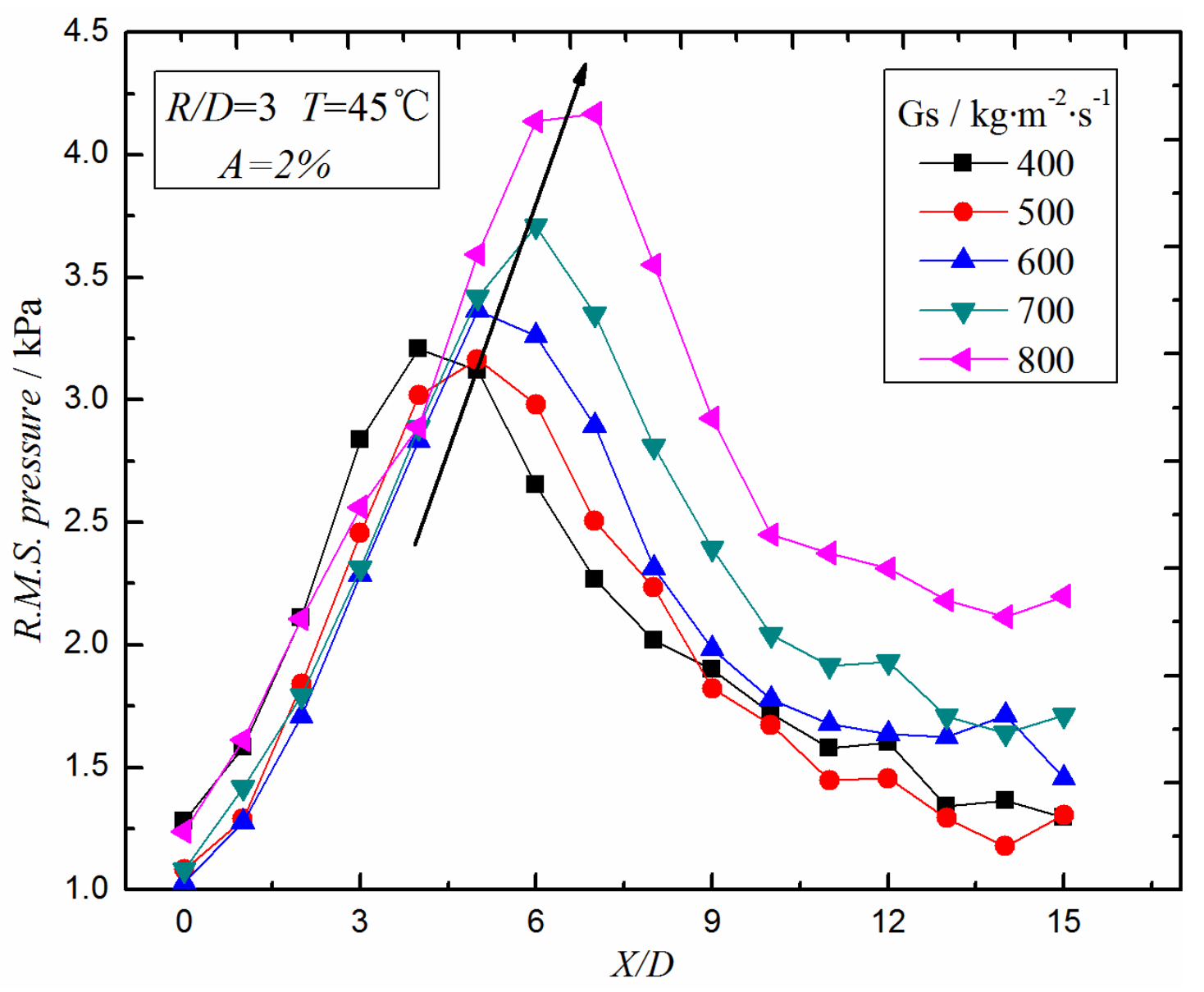




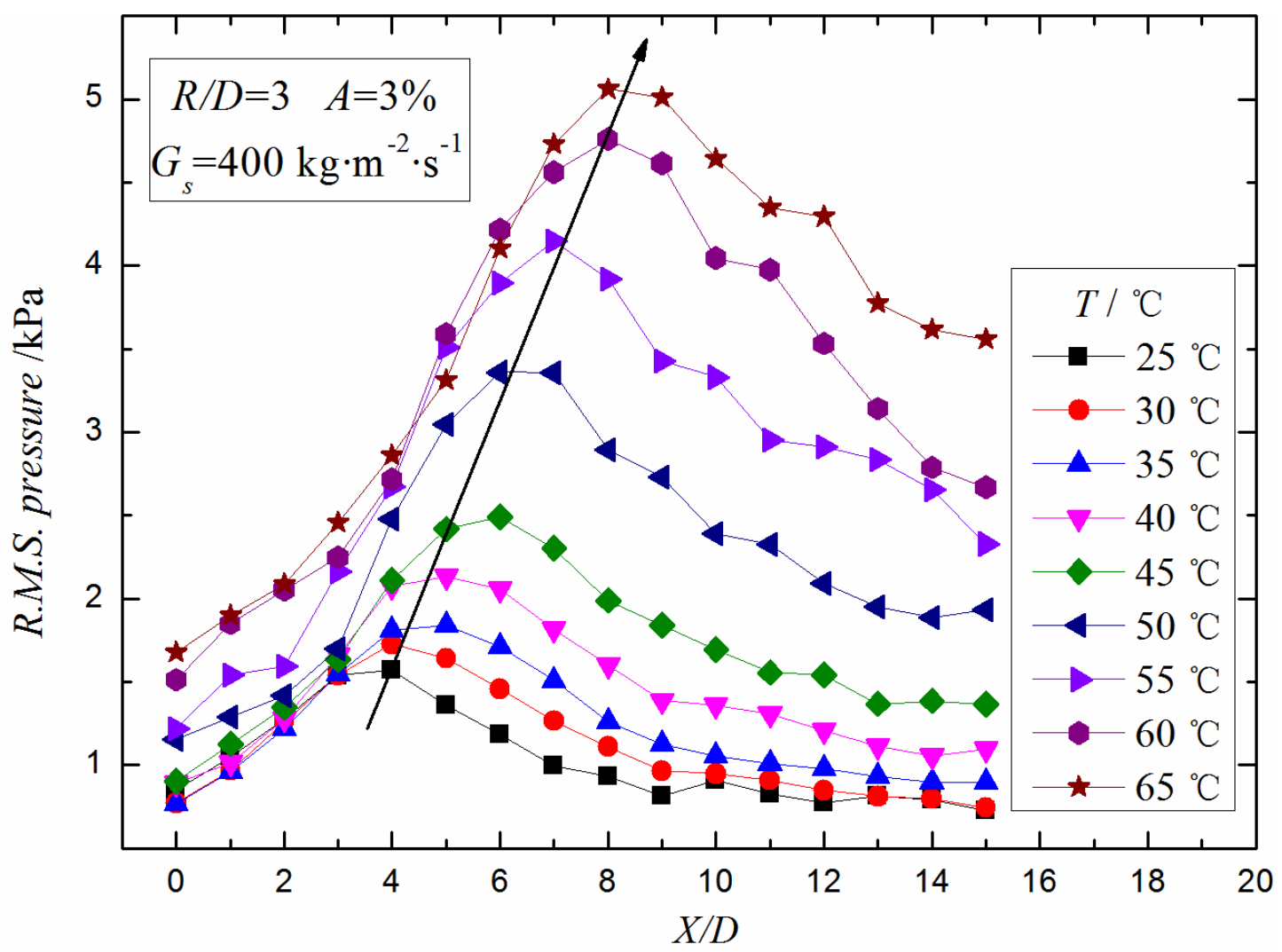




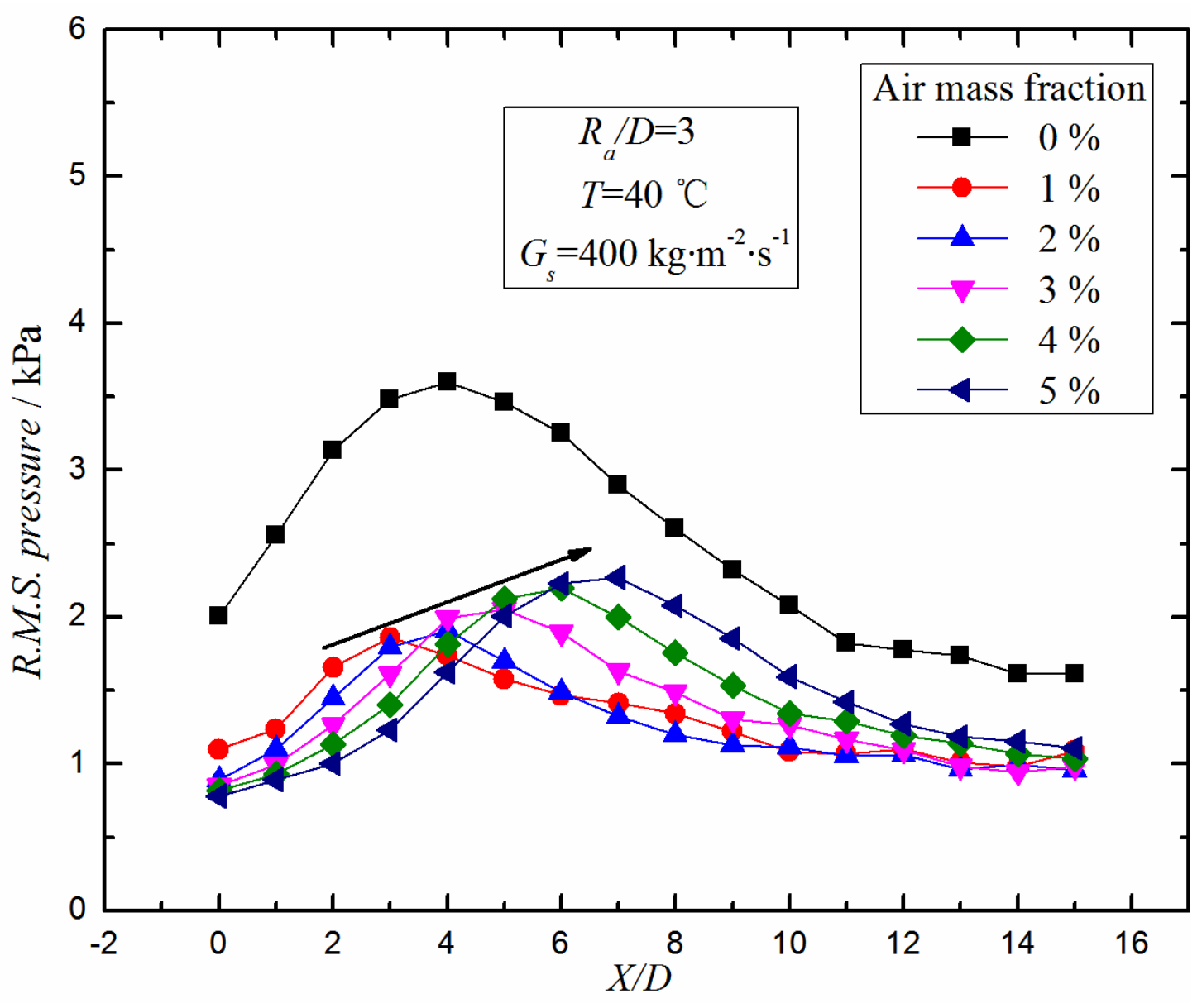




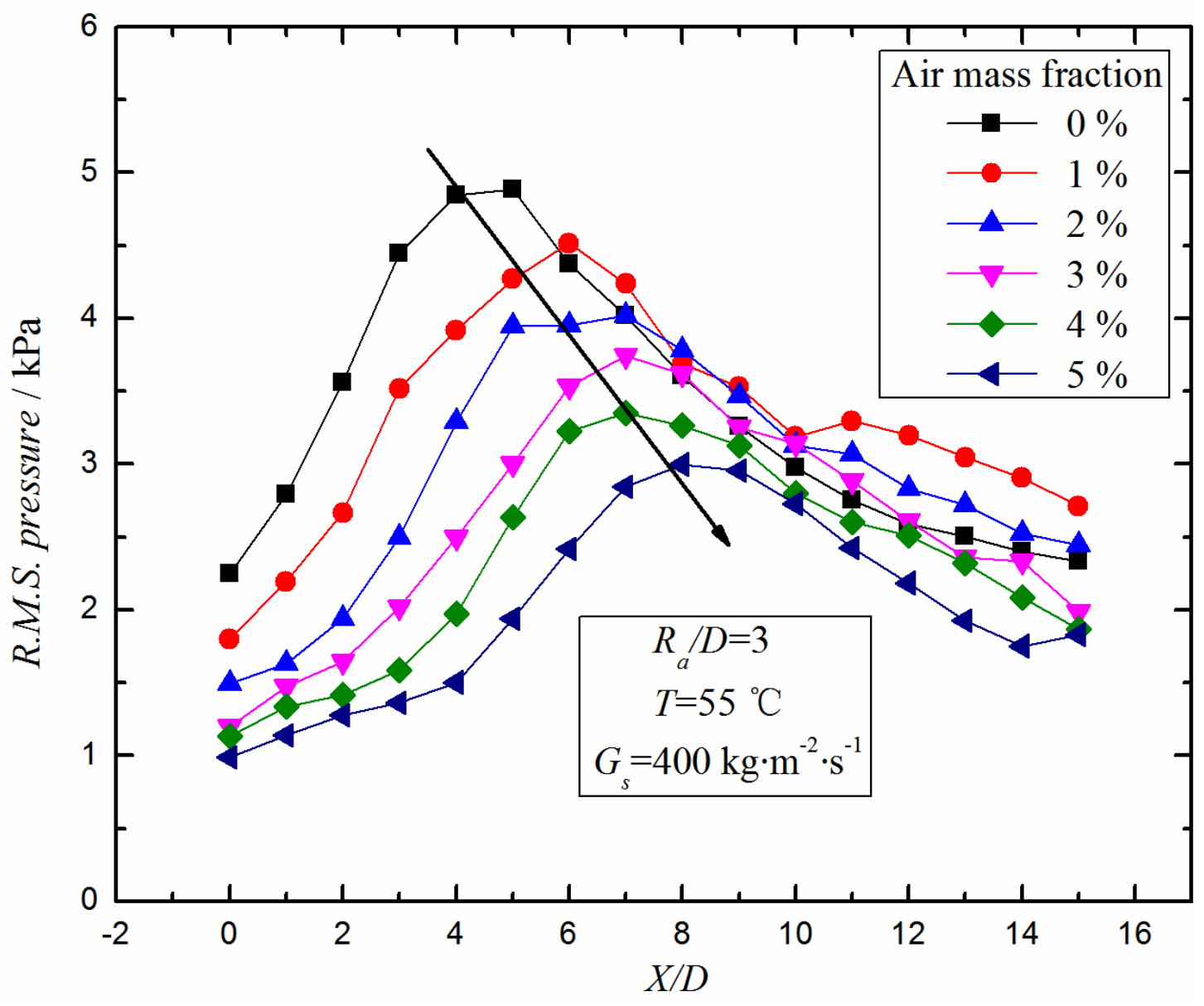




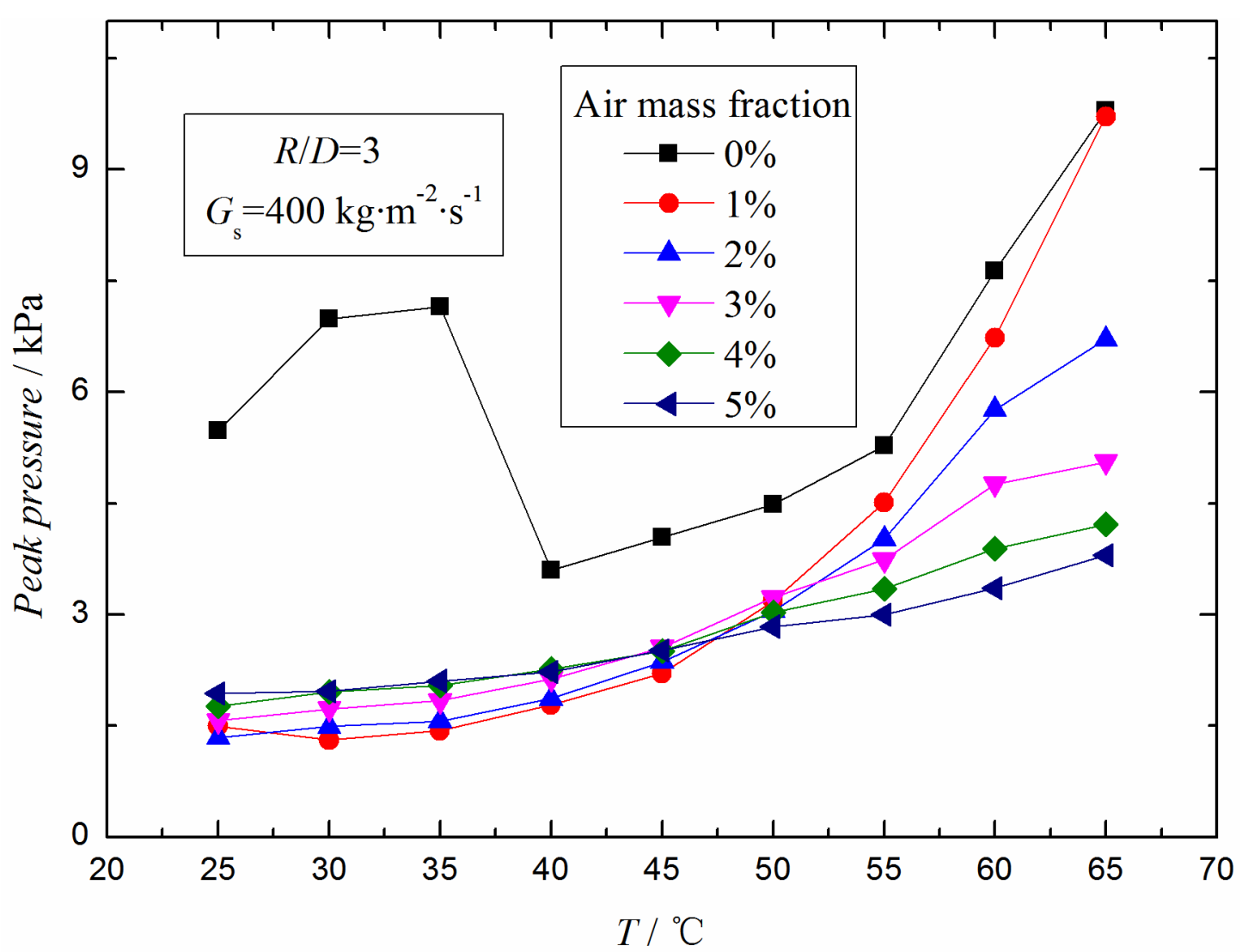




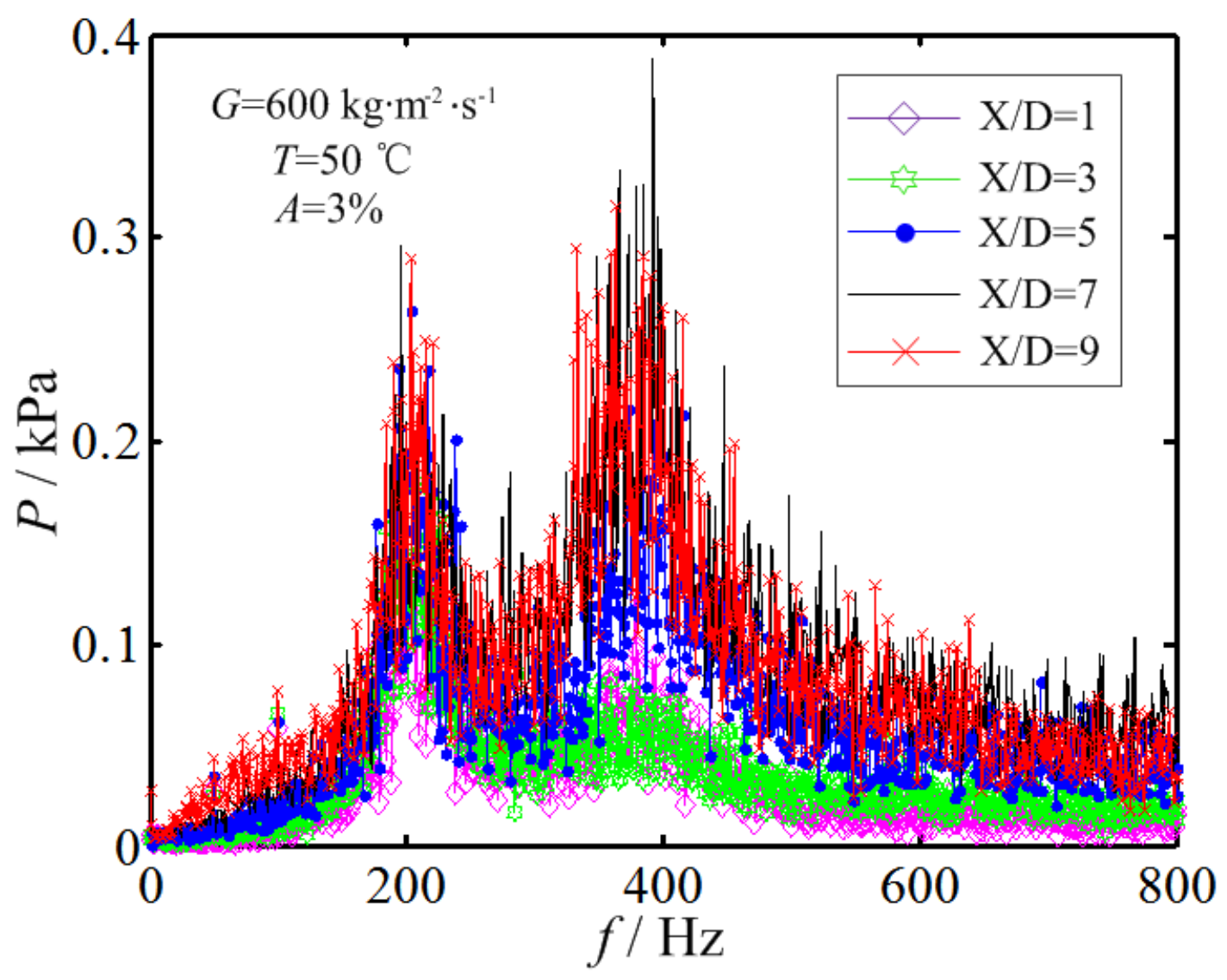




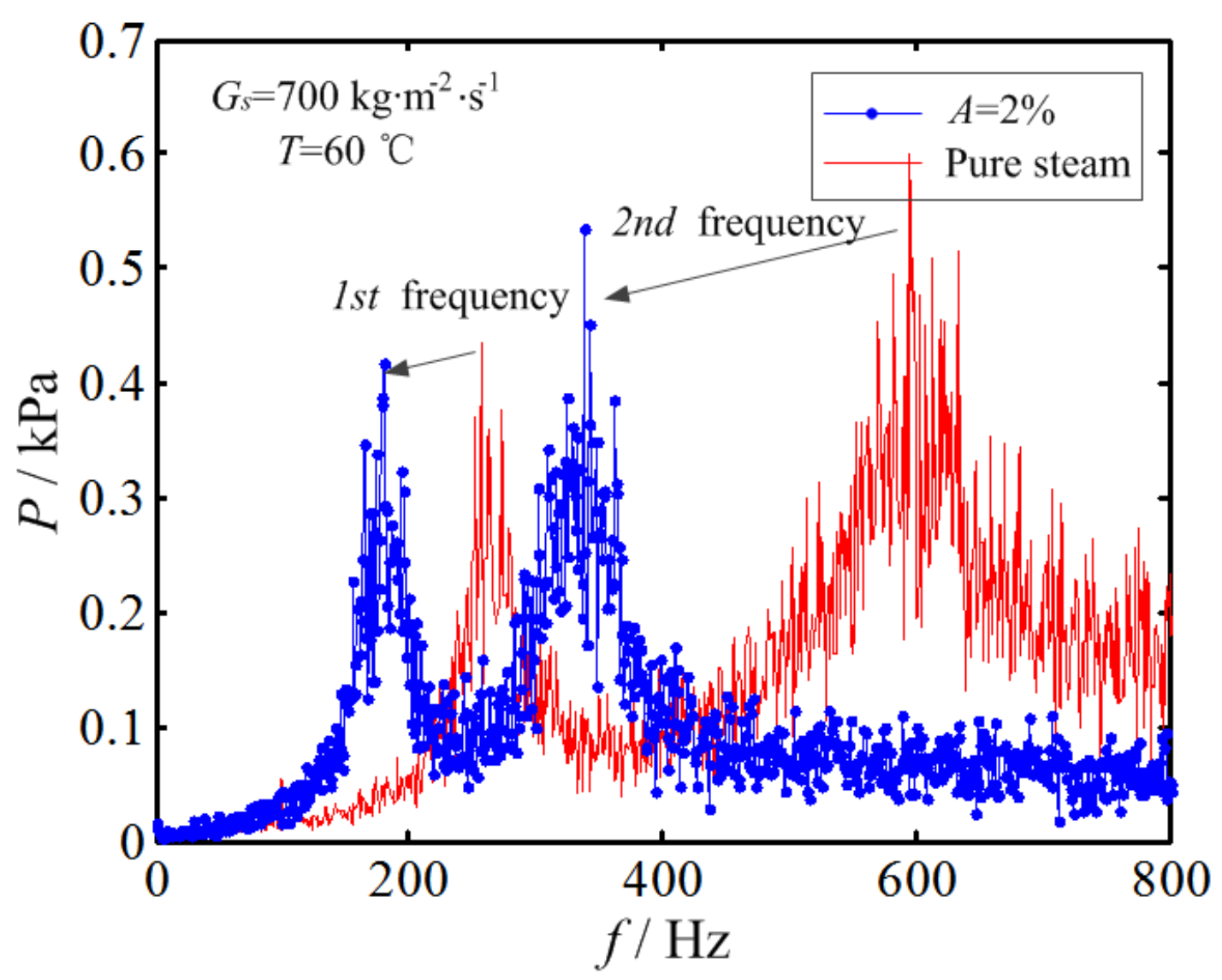




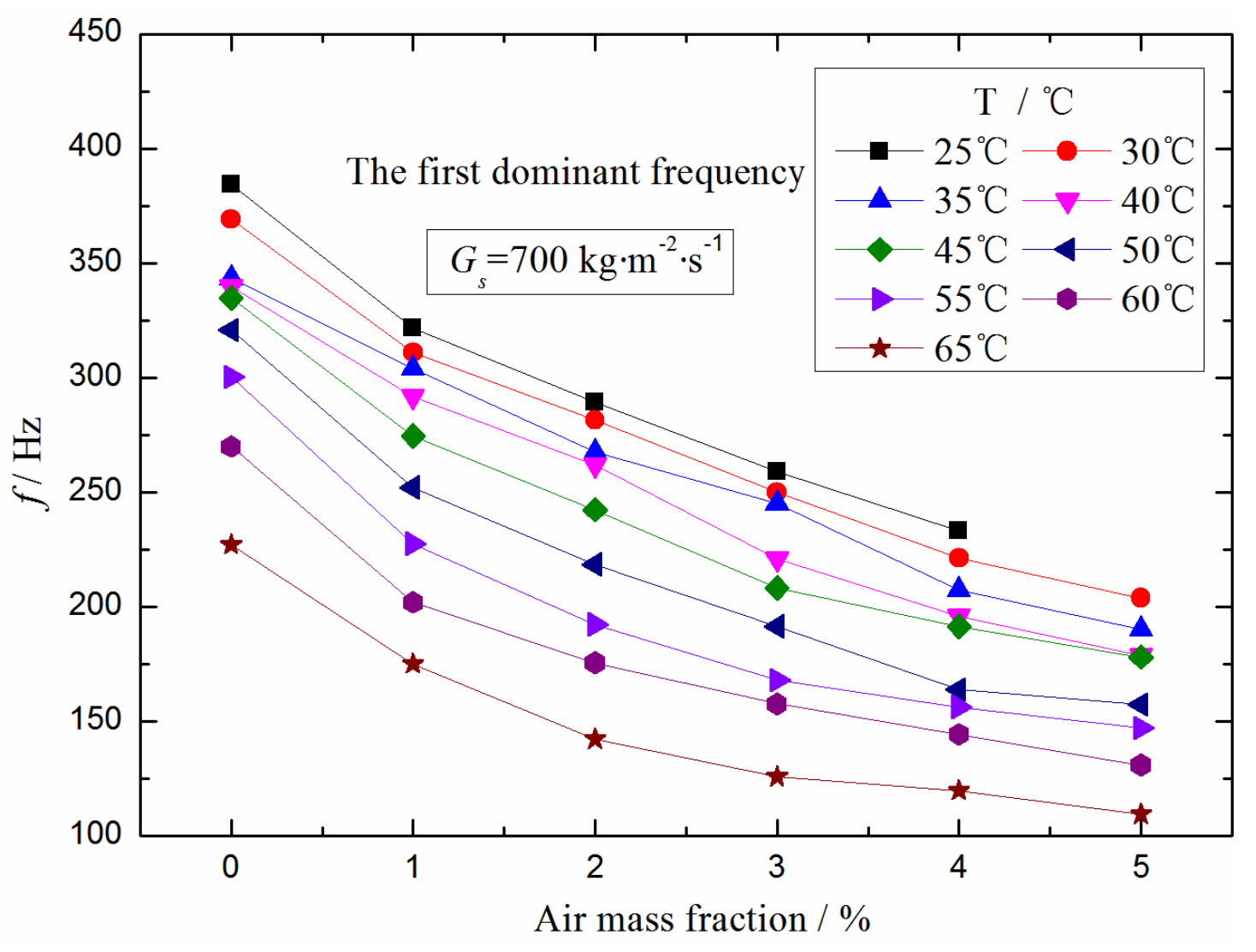




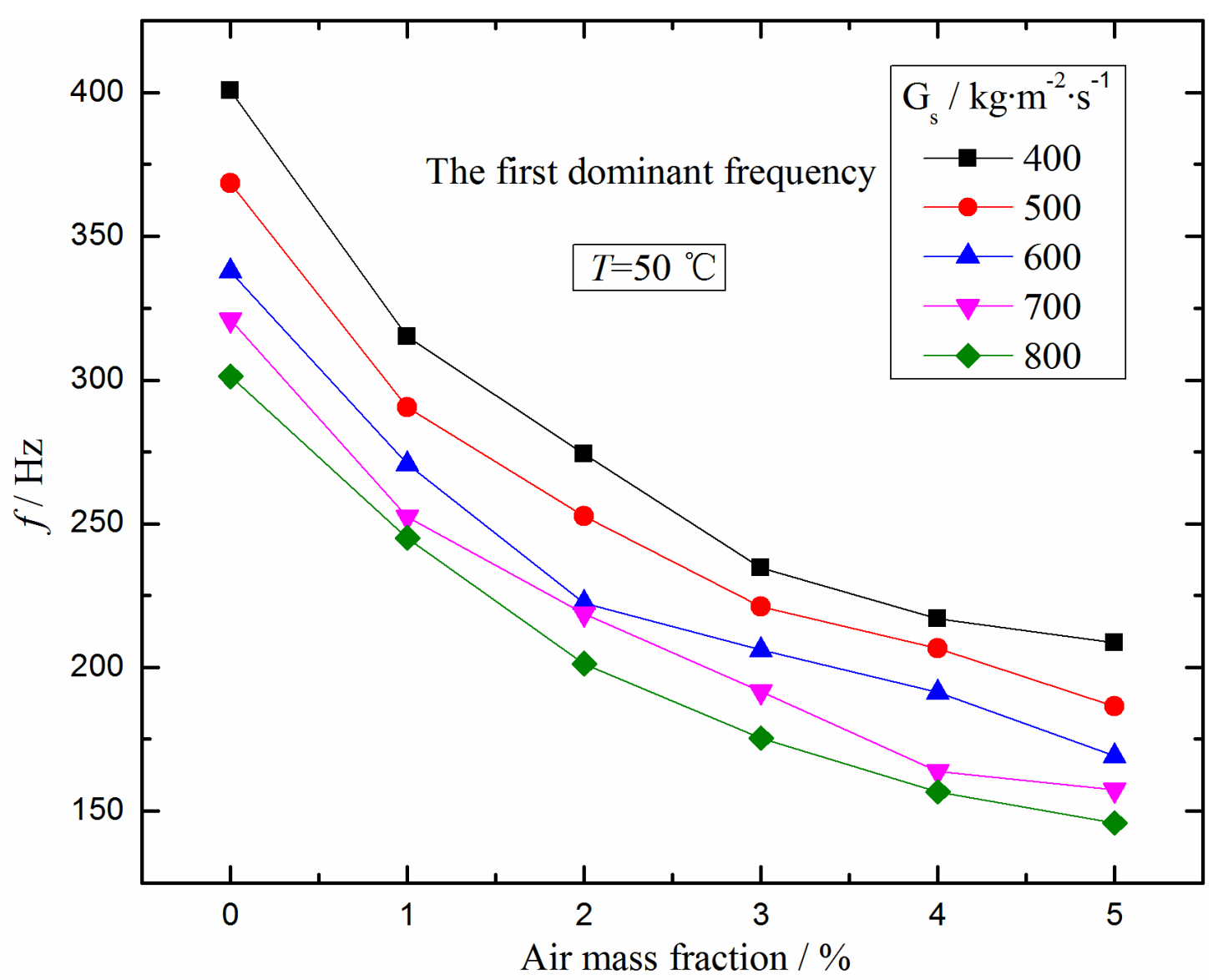




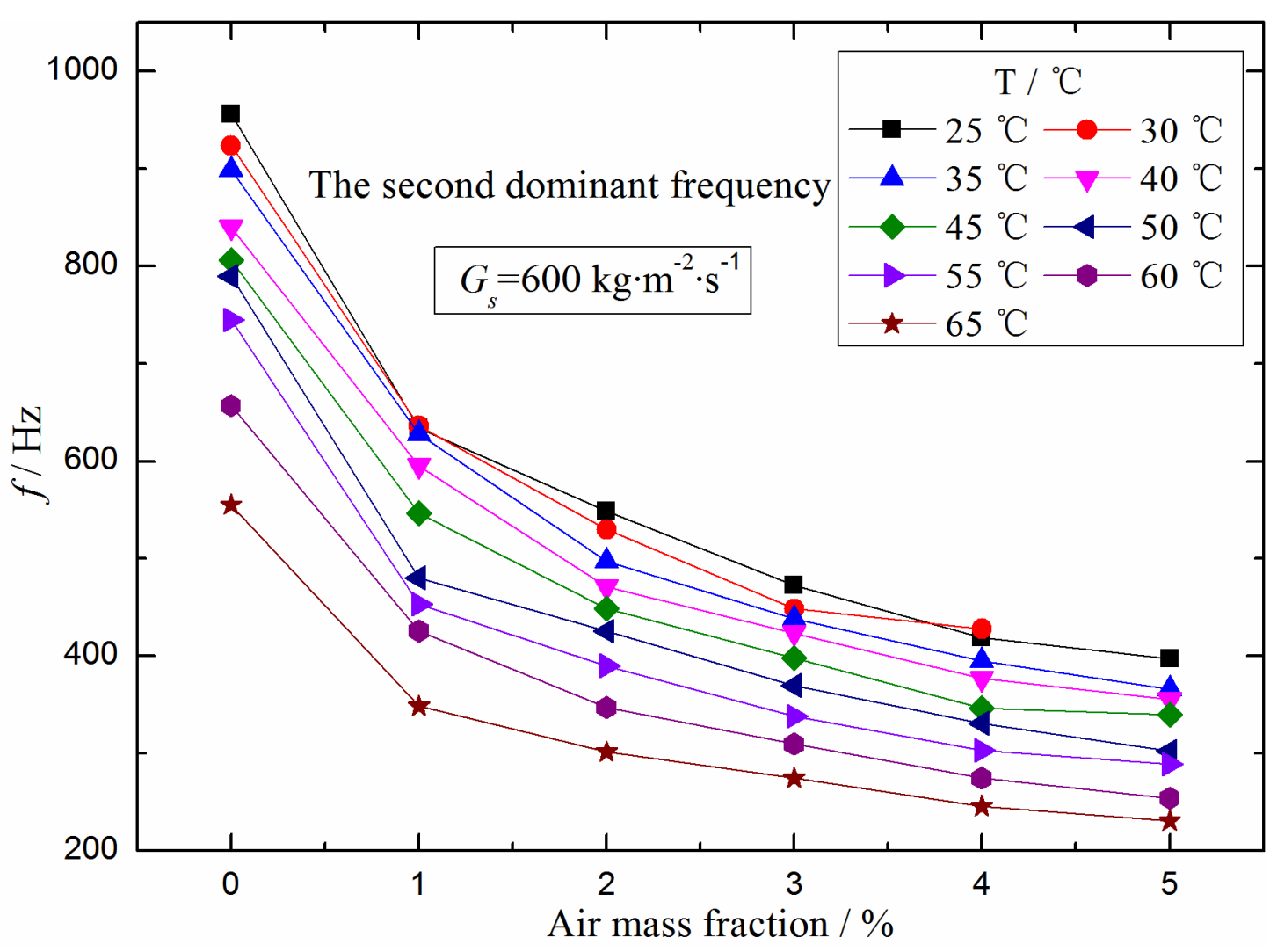




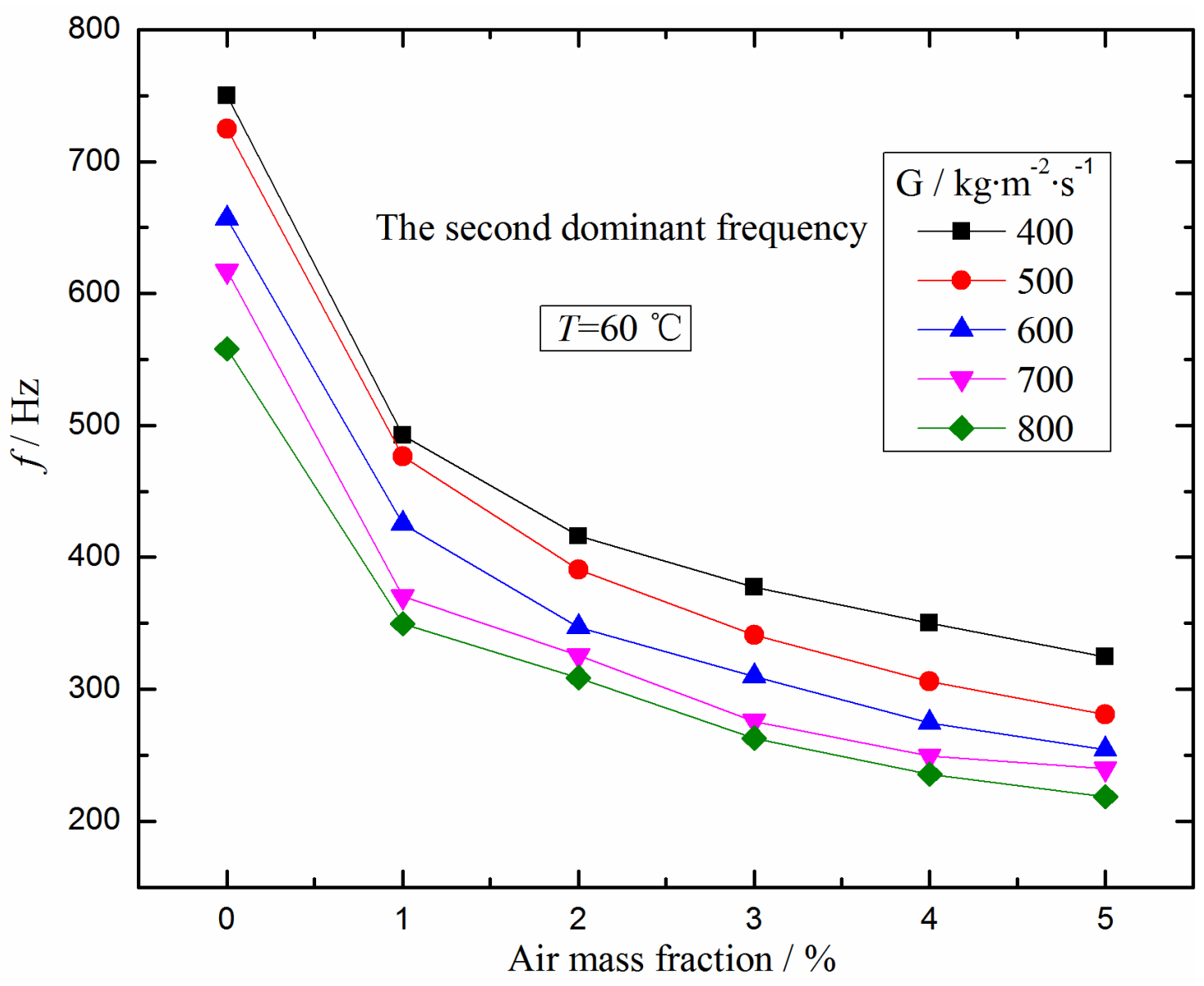




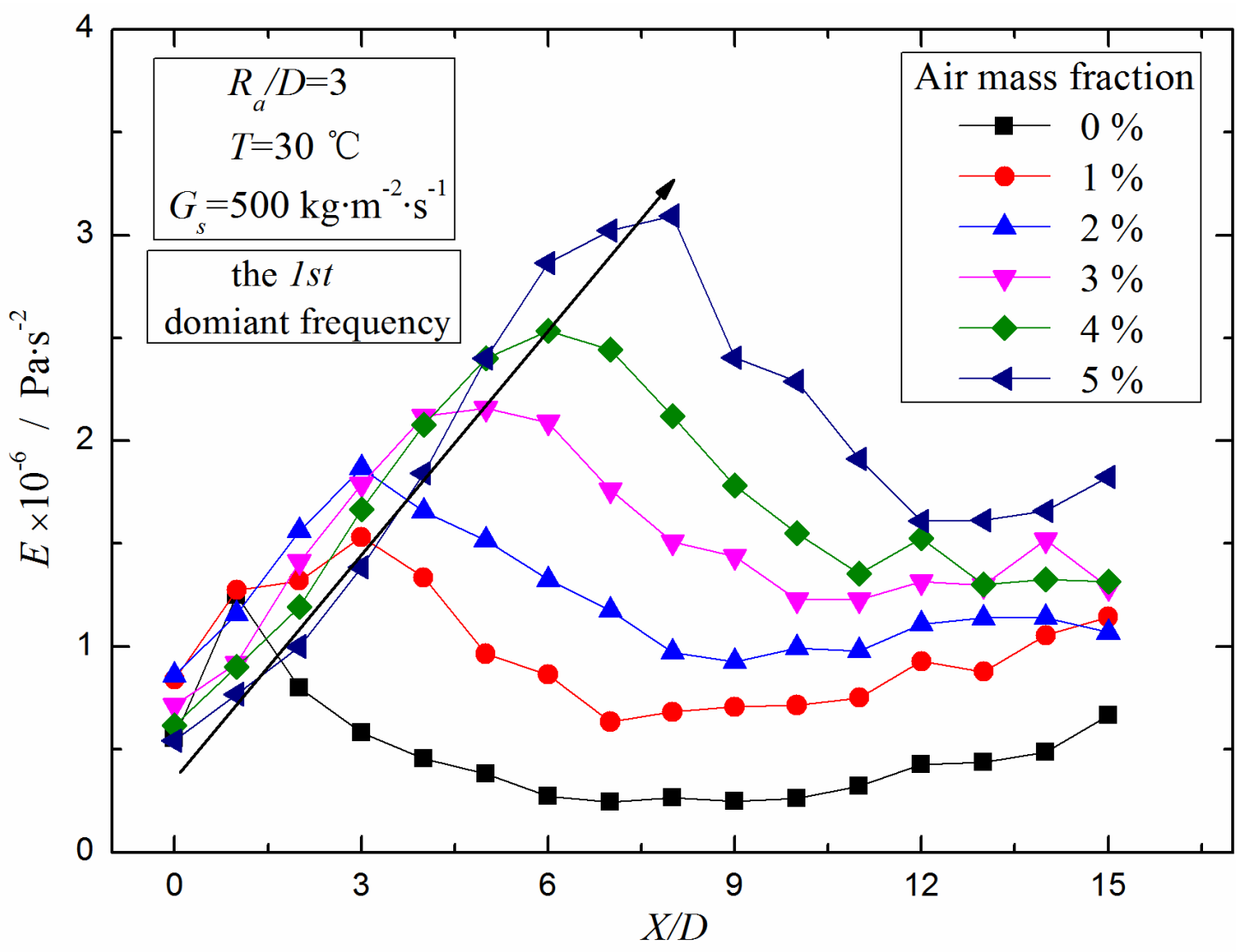




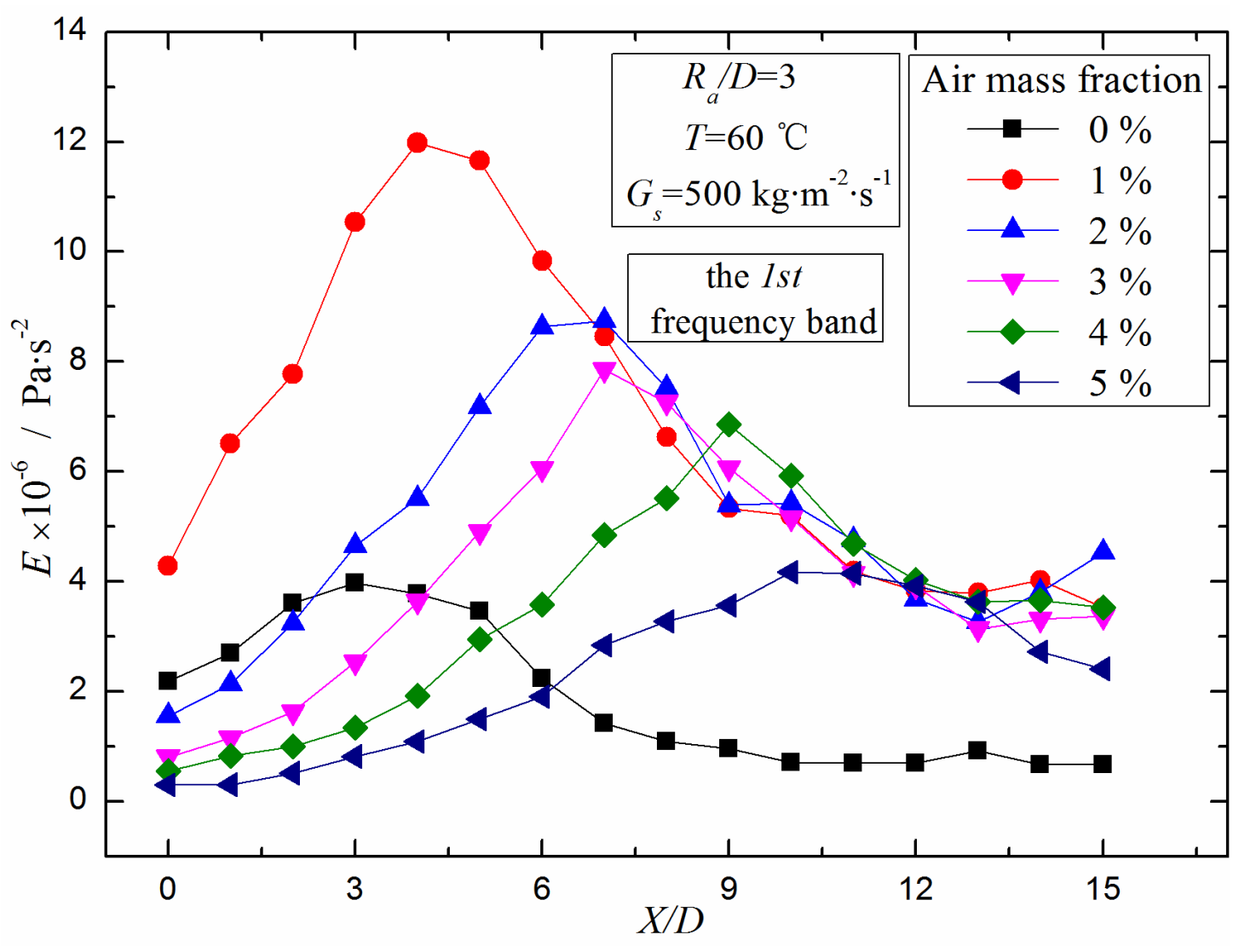




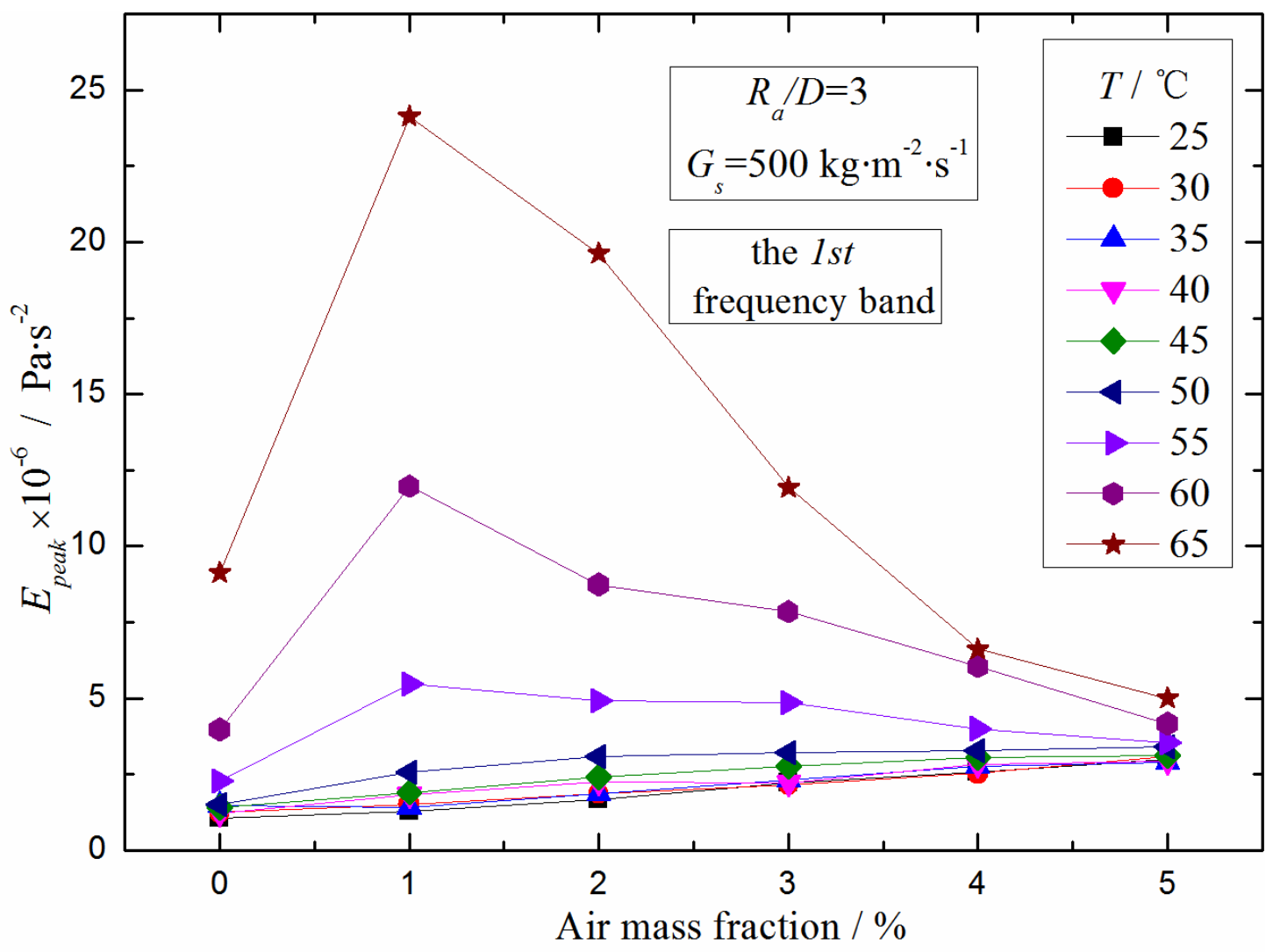




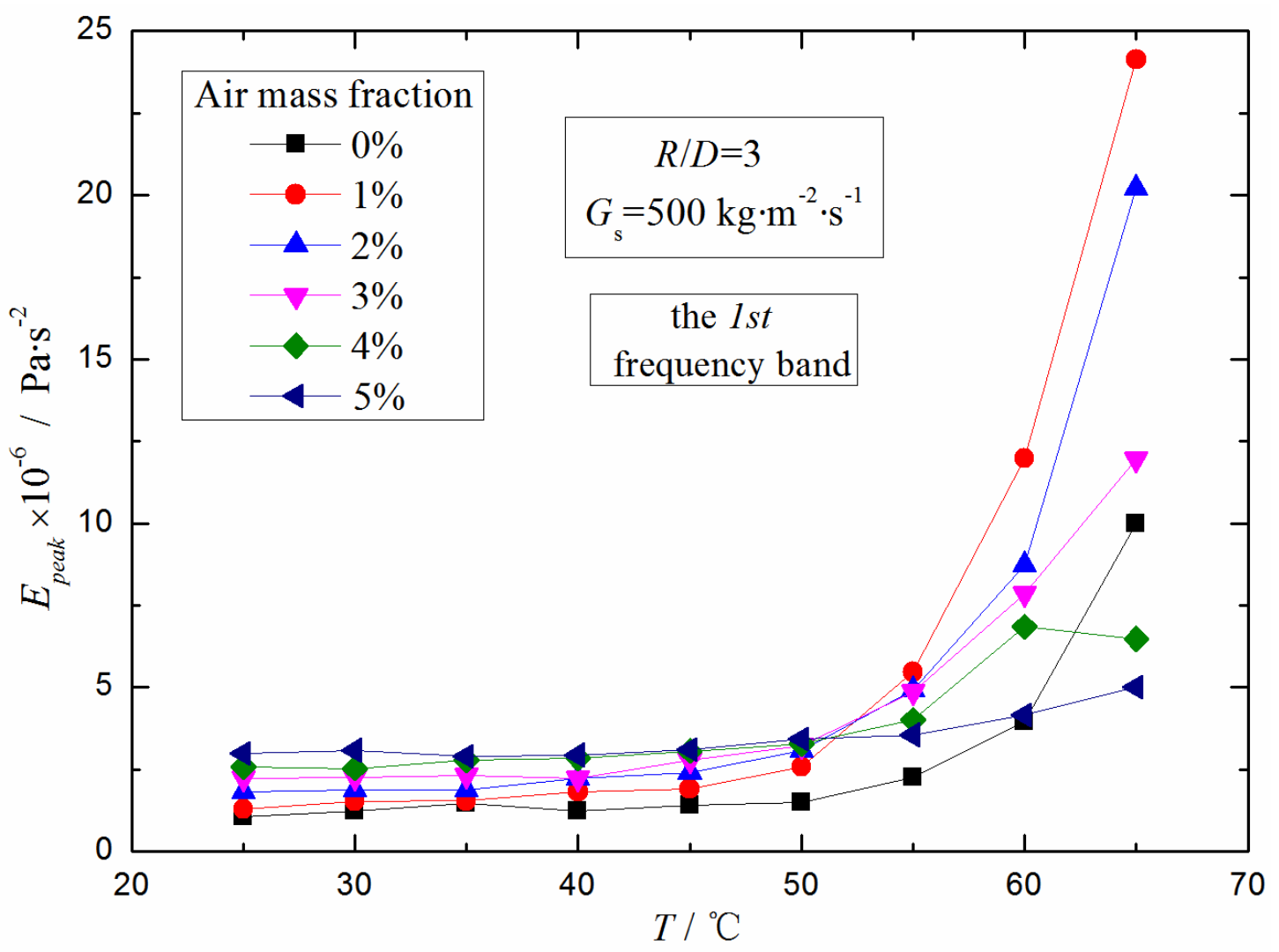




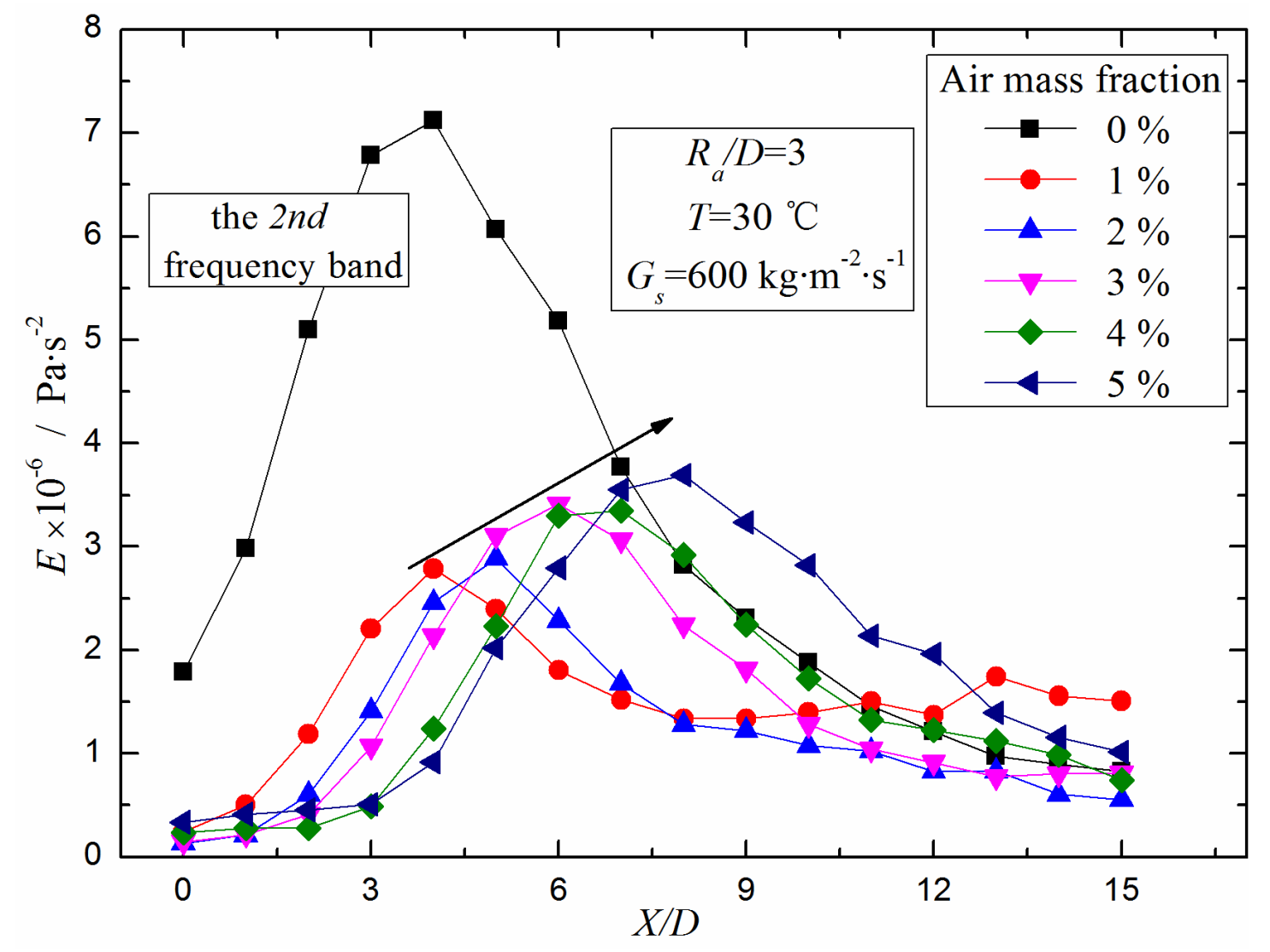




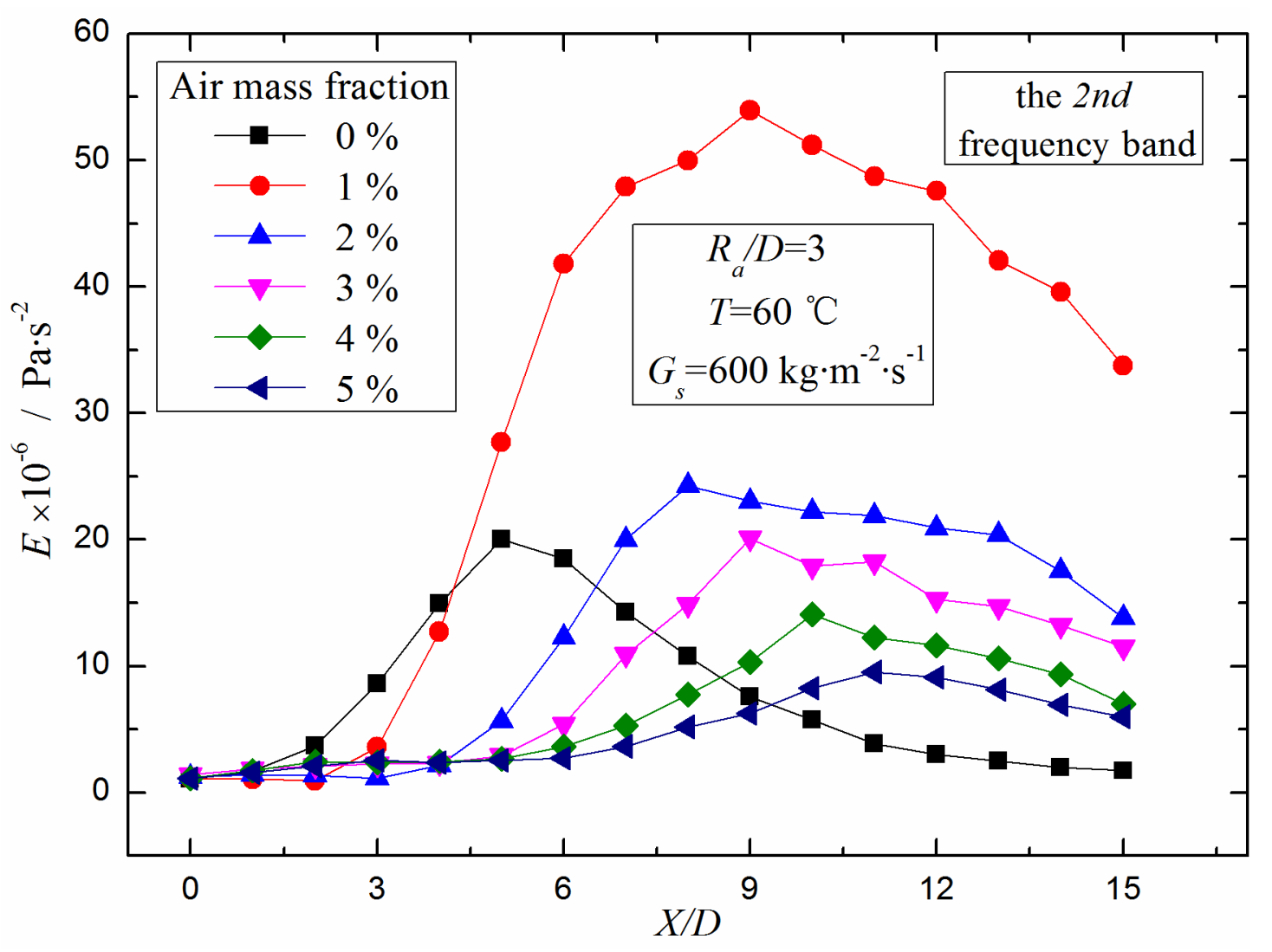




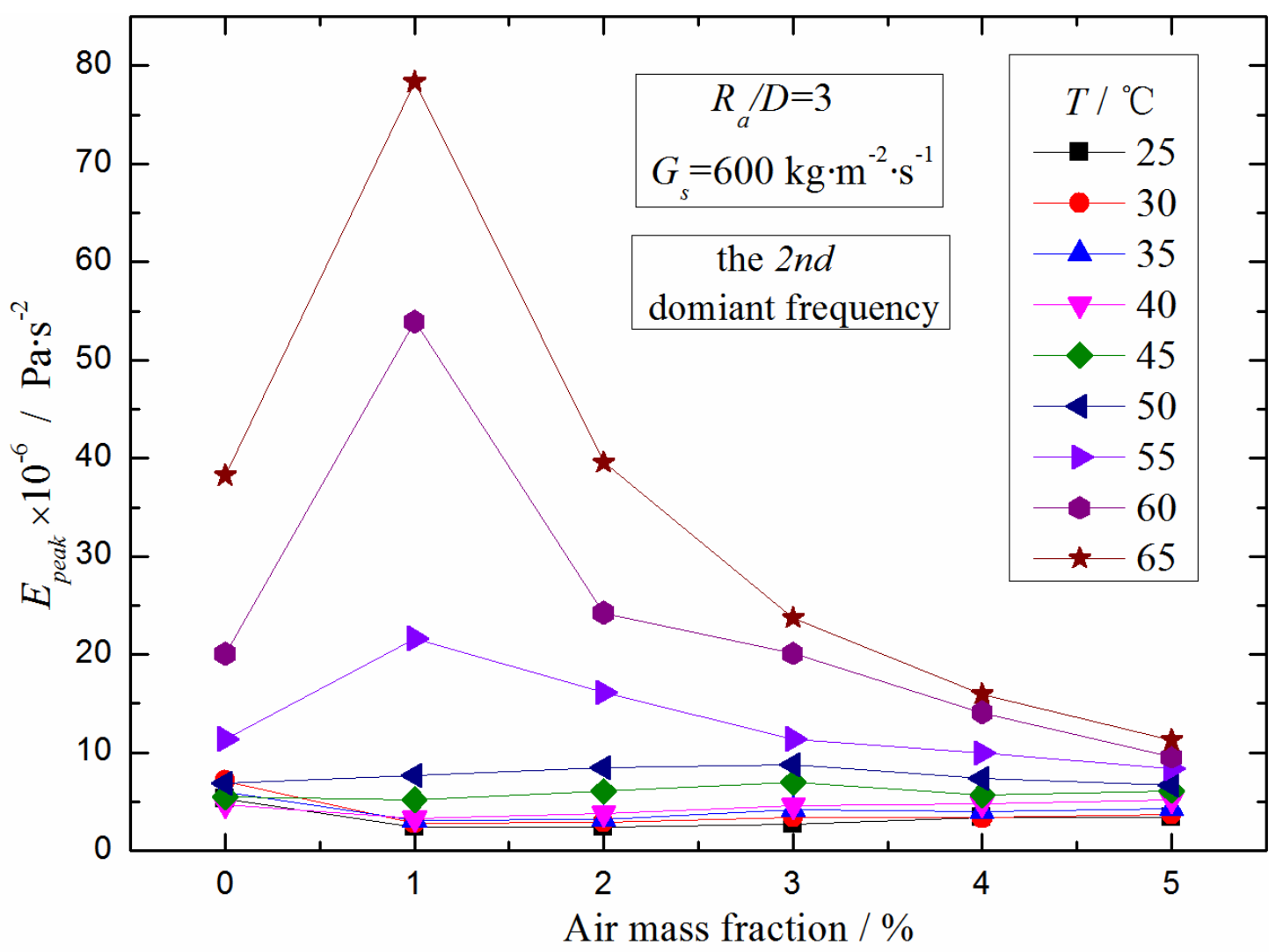




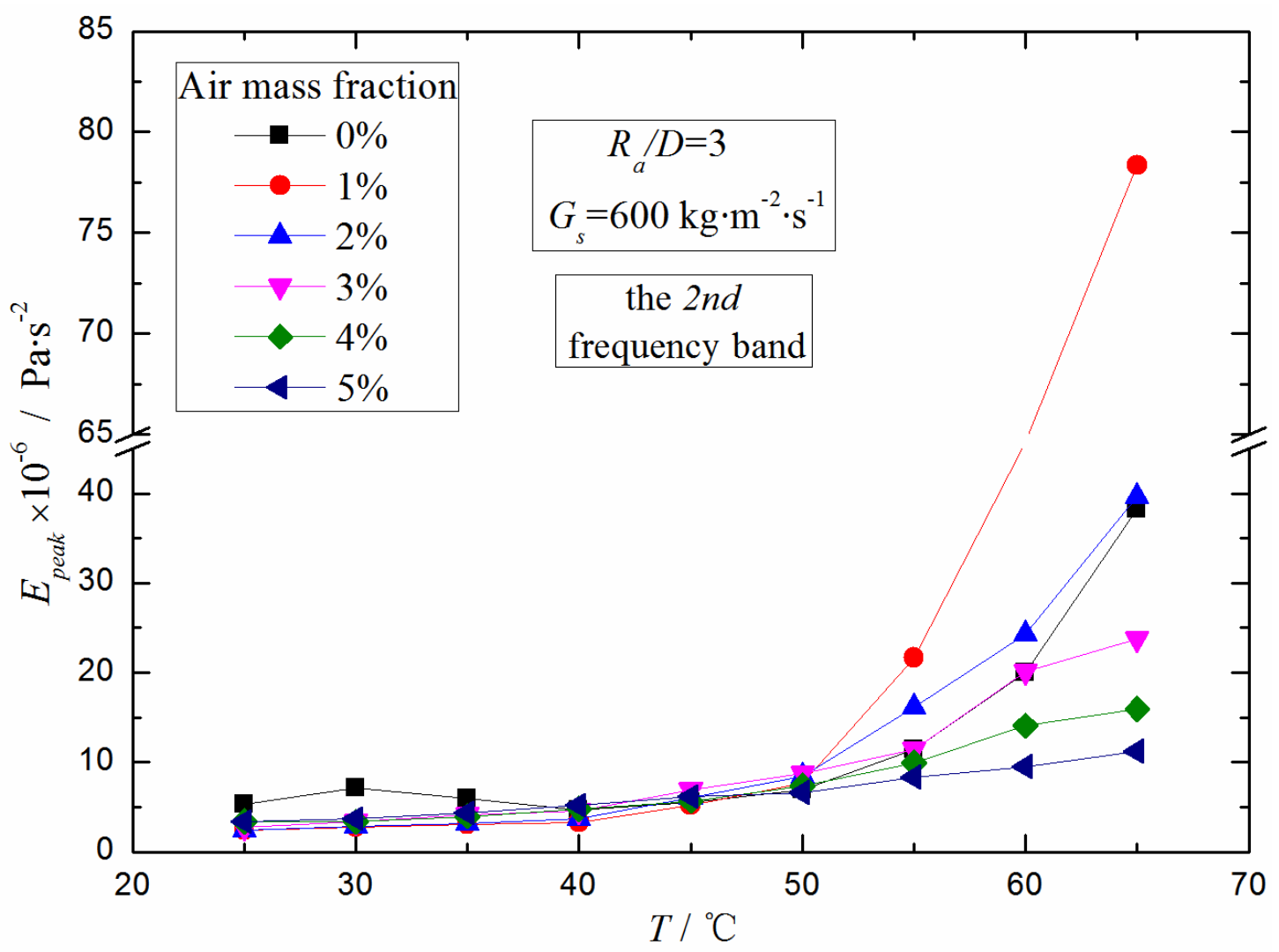



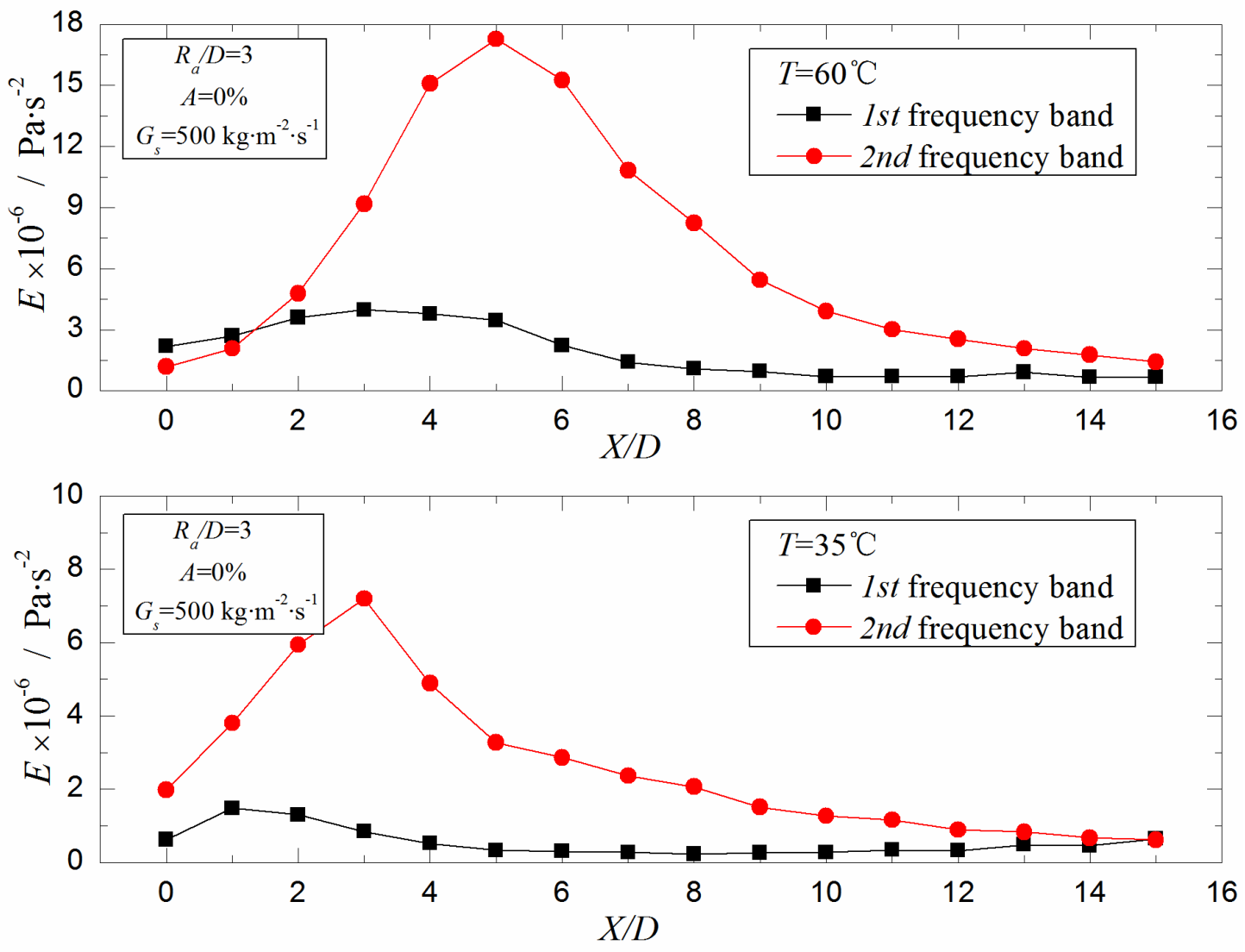

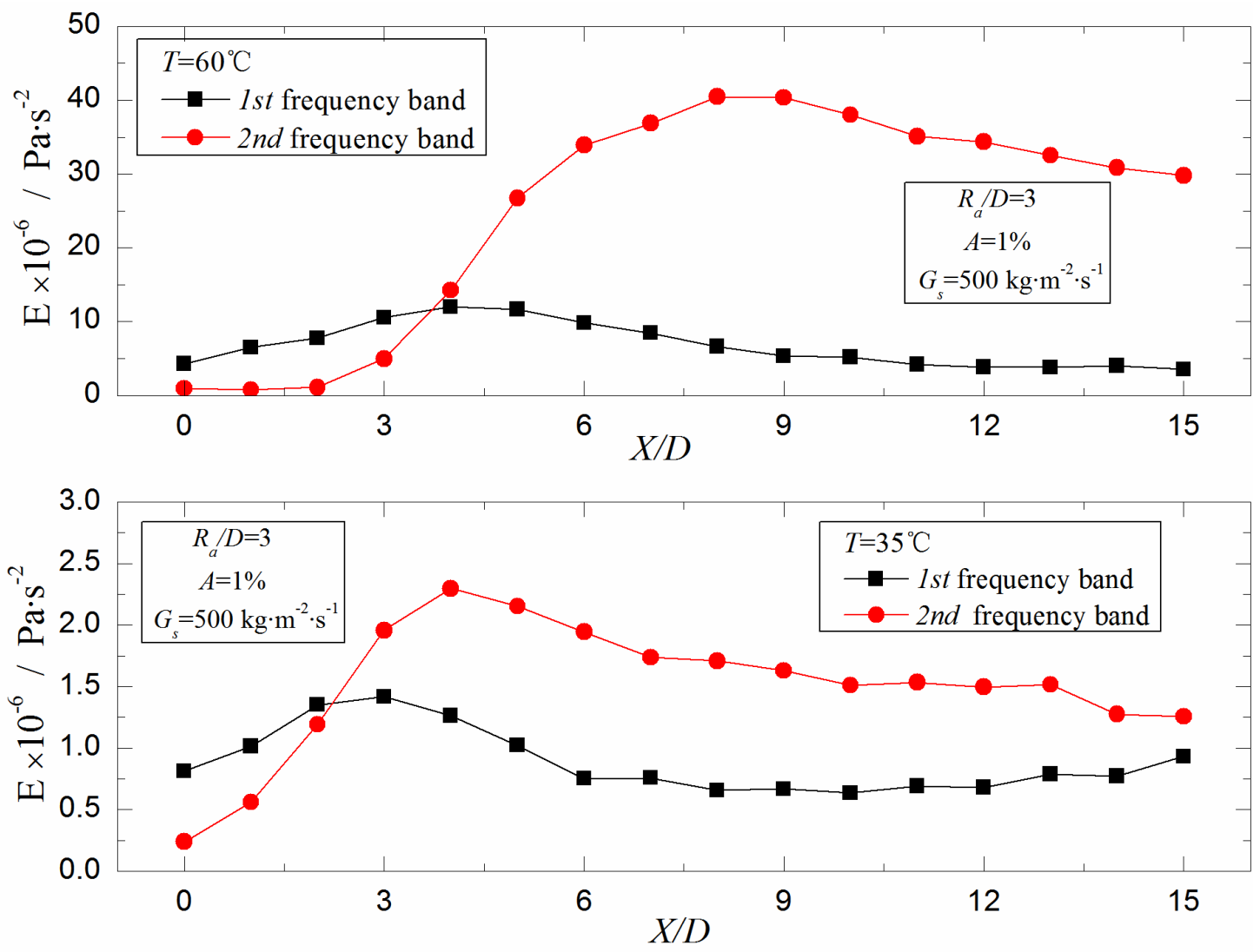

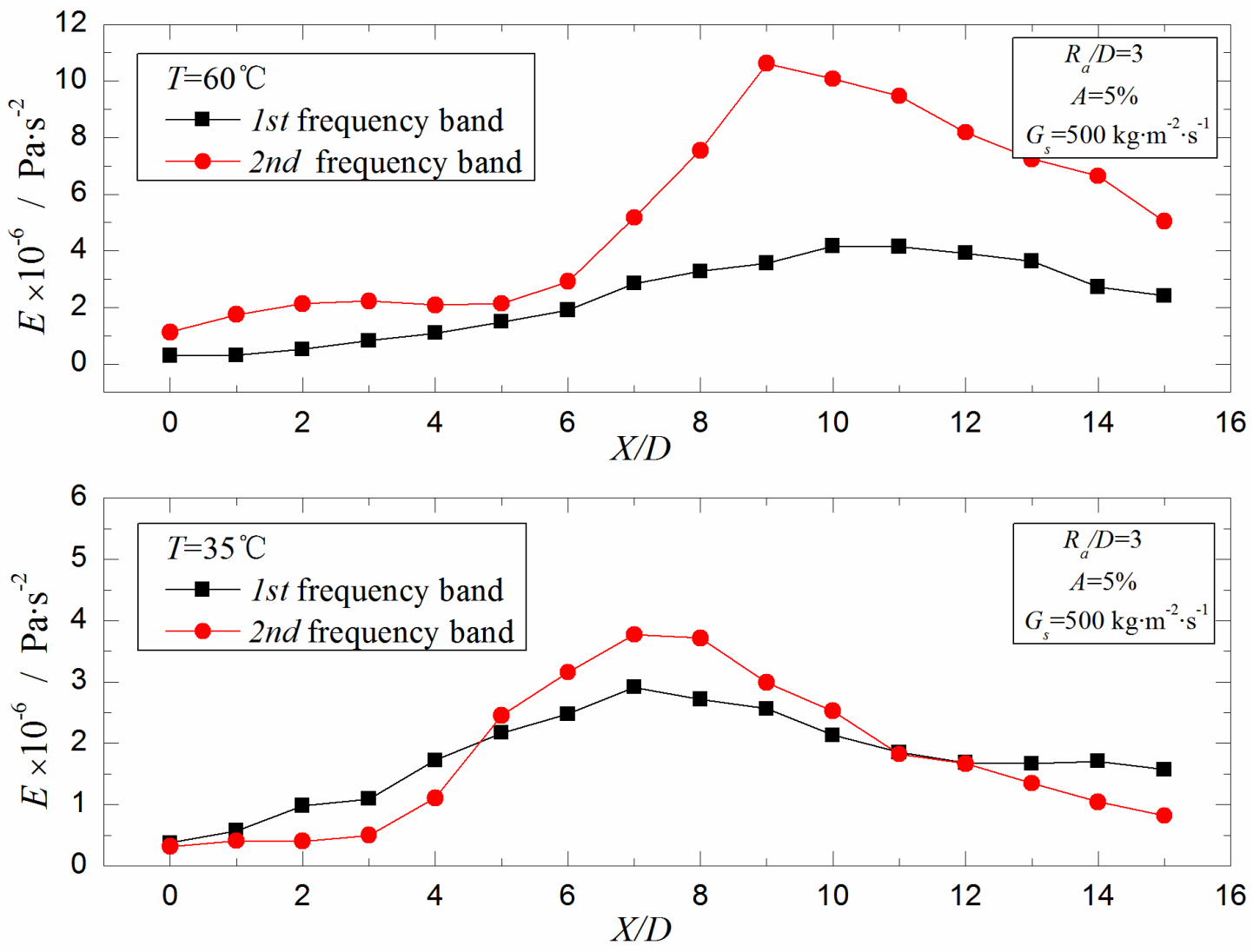


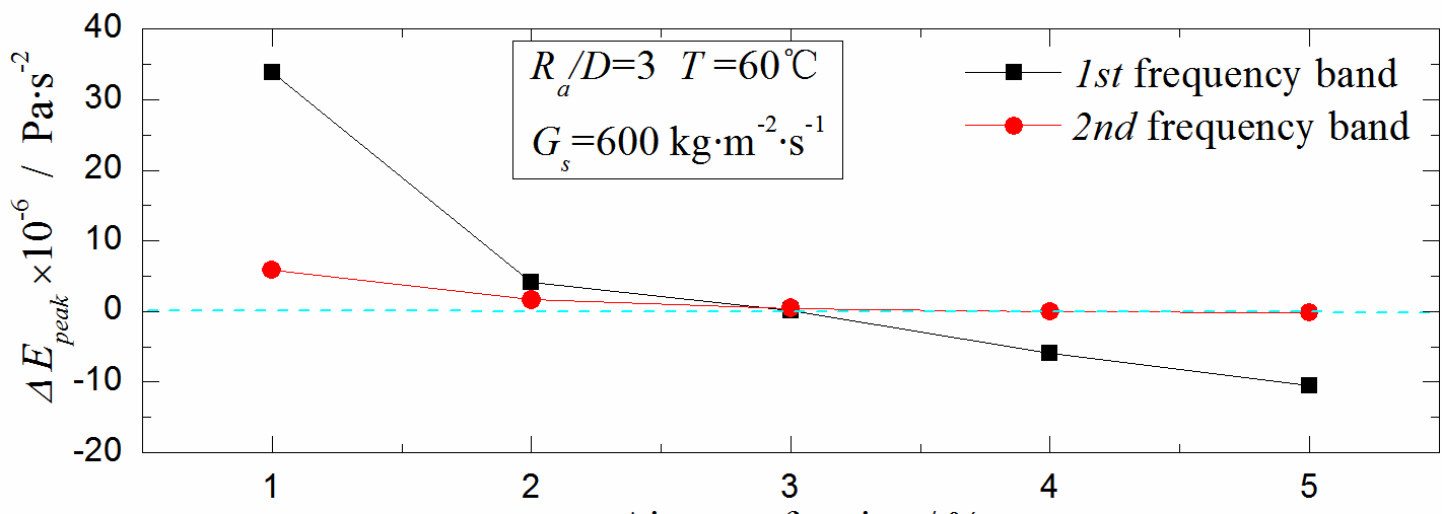

Air mass fraction / $\%$

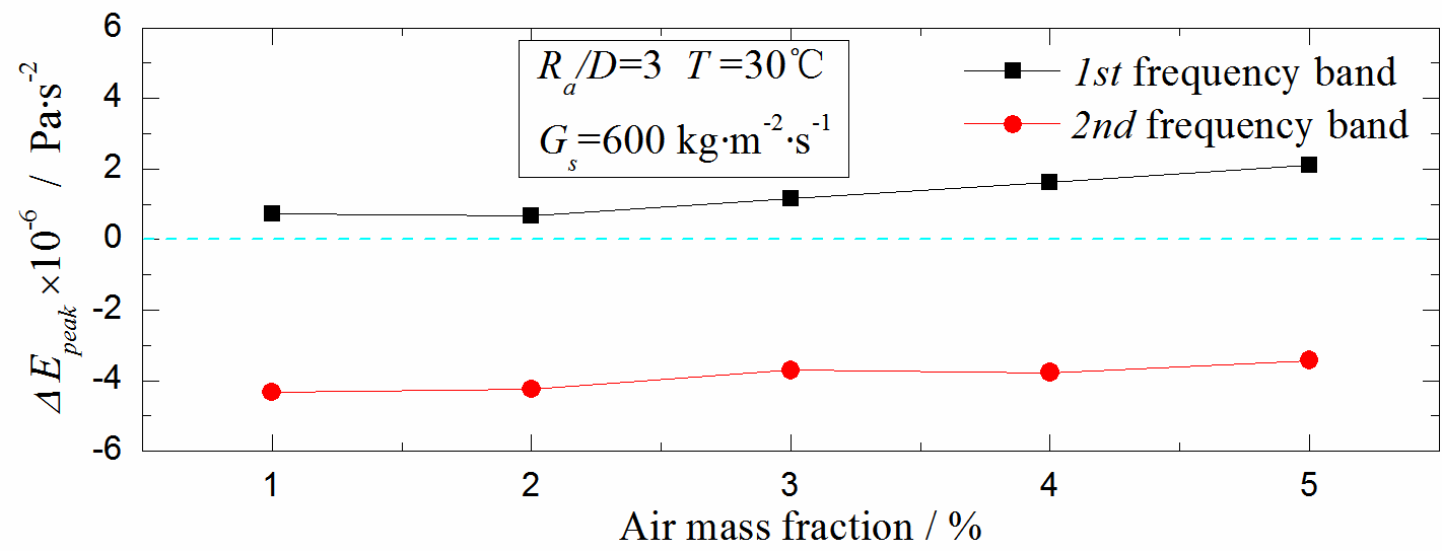

